\title{
ВЕЛИКОЕ НАСЛЕДИЕ Д.И. МЕНДЕЛЕЕВА: ЭВОЛЮЦИЯ ПЕРИОДИЧЕСКОГО ЗАКОНА И СИСТЕМЫ ХИМИЧЕСКИХ ЭЛЕМЕНТОВ
}

\begin{abstract}
О. В. Михайлов
ОЛЕГ ВАСИЛЬЕВИЧ МИХАЙЛОВ - доктор химических наук, профессор, главный научнылй сотрудник и профессор кафедры аналитической химии, сертификации и менеджмента качества Казанского национального исследовательского технологического университета (ФГБОУ ВО КНИТУ). Область научных интересов: теоретическая, неорганическая и координационная химия, соичология науки и технологий, наукометрия.E-mail: ovm@kstu.ru,olegmkhlv@gmail.com.
\end{abstract}

Россия, 420015 Казань, ул. К. Маркса, 68, ФГБОУ ВО «КНИТУ».

Представлены данные, касающиеся формулировки Периодического Закона Д.И. Менделеева и отдельных графических вариантах его интерпретачии, предложенных в разное время за 150 лет с момента открытия данного Закона. Констатировано, что, несмотря на наличие весьма значительного (несколько сотен) количества этих вариантов, практическое приложение получили лишь два табличных варианта Периодической системы химических элементов - т.н. «короткопериодический», предложенный Д.И. Менделеевым, и т.н. «длиннопериодический», предложенный А. Вернером, который рекомендован Международным Союзом по чистой и прикладной химии (IUPAC) для практического использования. Предложена модификачия данных табличных вариантов, начеленная на преодоление их недостатков. Обсуждены также вопрос о существовании верхней гранищы Периодической системы и вероятные перспективы получения сверхтяжельх элементов с зарядом ядра $Z>110$, в частности новой их категгрии - 5 g-элементов.

Ключевые слова: Периодический Закон Д.И. Менделеева, Периодическая система химических элементов, «короткопериодический» вариант, «длиннопериодический» вариант.

\section{GREAT HERITAGE D.I. MENDELEEV: EVOLUTION OF THE PERIODIC LAW AND SYSTEM CHEMICAL ELEMENTS}

\author{
O. V. Mikhailov
}

68, Karl Marx street, Kazan, 420015. Kazan National Research Technological University.

The data concerning the definition of the D.I. Mendeleev's Periodic Law and separate graphic variants of its interpretation, proposed at different times for 150 years since the opening of the given Law. It has been stated that, despite the presence of a very significant (several hundred) number of these variants, only two tabular ones of the Periodic Table of chemical elements - so-called "short-periodical" variant proposed by D.I. Mendeleev, and so-called "long-periodical" proposed by A. Werner, recommended by the International Union of Pure and Applied Chemistry (IUPAC) for practical use - received practical applications. A modification of these tabular variants which aimed at overcoming their shortcomings, was proposed. The question of the existence of the upper limit of the Periodic Table and the probable perspectives for obtaining superheavy elements with a nuclei charge of $Z>110$, in particular their new category, $5 g$-elements, were also discussed.

Key words: D.I. Mendeleev's Periodic Law, Periodical system of chemical elements, "short-periodical" variant, "long-periodical" variant. 
Наступивший 2019 год является особенным годом для химической общественности как в России, так и за ее пределами, поскольку именно в нем так или иначе будет отмечаться 150-летие с момента появления на свет Периодического Закона изменения свойств химических элементов и образуемых ими химических соединений, сформулированного нашим великим соотечественником - Дмитрием Ивановичем Менделеевым. И хотя этот самый закон входит не в число основных законов химии, a - как это не прозвучит парадоксально! - в число 500 основных законов хоть и тесно связанной с ней, но все же другой науки - физики, тем не менее он был и остается в числе именно тех закономерностей химической науки, которые определяют ее современное лицо. Настоящая статья и посвящена проблематике, связанной со спецификой интерпретации данного закона.

\section{Введение}

Практически сразу же после того, как в химии сформировалось хоть какое-то (пусть и весьма примитивное по нынешним меркам) представление о химических элементах, многие представители этой науки стали задумываться о том, насколько, во-первых, велико количество этих самых элементов, а во-вторых, можно ли усмотреть какую-либо взаимосвязь между их свойствами и иерархией их взаимного расположения в рамках некой системы, эти элементы включающей $[1,2]$. Ответ на первый из этих вопросов остается открытым и по сей день, и на этот счет имеются весьма различные мнения - от того, что, хотя теоретически согласно современной теории строения атома их число безгранично, реальное их количество может составлять порядка 150 , и современная наука уже недалека от этого предела, до того, что их количество находится в диапазоне 50-60 миллионов (!) [3]. С ответом же на второй вопрос дело оказалось более простым: были предприняты достаточно многочисленные и целенаправленные попытки создания системы химических элементов, начало которым было положено в работах И. Деберейнера, установившего в 1829 г. т.н. «закон триад», и Л. Гмелина (1843), составившего свою таблицу известных на тот момент элементов на основе их химической классификации. Следующим шагом на пути к открытию периодического закона стали т.н. дифференциальные системы, направленные на выявление общих закономерностей в изменении атомного веса элементов. В 1850 г. М. Петтенкофер заметил, что атомные веса некоторых элементов отличаются друг от друга на ве- личину, кратную восьми, и в связи с этим высказал гипотезу, что элементы являются сложными образованиями, состоящими из каких-то субэлементарных частиц; годом позже нечто похожее отметил и Ж. Дюма. В 50-60-е годы XIX в. различные варианты дифференциальных систем химических элементов были предложены Э. Ленсеном, Д. Куком, У. Одлингом, Дж. Глэдстоном и А. Штреккером. Последующее развитие и совершенствование систематики химических элементов связано с идеей периодичности, смысл которой состоит в том, что для каждого конкретного элемента через определенный диапазон атомных масс имеет место наличие другого элемента, химические свойства которого весьма близки к свойствам данного конкретного элемента [1]. Впервые она была реализована А. Шанкуртуа в 1862 г., предложившим винтовой график элементов, расположенных в порядке возрастания атомных весов - т.н. «земную спиpaль» (vis tellurique). Признания среди современников такая система не получила, однако заложенная в ней идейная подоплека дала толчок к новым попыткам систематизации, нашедшим свое отражение в работах Дж. Ньюлендса $[4,5]$ и особенно Л. Мейера $[6,7]$, которого можно считать ближайшим предшественником Д.И. Менделеева. Ближайшим - потому что предложенная им система химических элементов была наиболее близкой к той, которой предложил в качестве своего первого варианта систематики Д.И. Менделеев в своем эпохальном труде [8]. Нисколько не умаляя заслуги и вклада его предшественников в становлении системы химических элементов, нельзя не отметить следующего чрезвычайно важного обстоятельства: ВСЕ без исключения «доменделеевские» попытки классификации и систематизации химических элементов по существу представляли собой лишь частные (причем порой чисто случайные) наблюдения и сопоставления [2] и, соответственно, приводили лишь к тем или иным частным же обобщениям, лишенным тех основных признаков, что должны быть присущи ЗАКОНУ ПРИРОДЫ. Д.И. Менделеев выделяется на фоне всех прочих творцов системы химических элементов не тем, что его система была более совершенной по сравнению с другими, и не тем, что его имя уже почти полтора столетия упоминается (и, уверен, будет упоминаться и в дальнейшем) во всем мире, когда речь заходит о системе химических элементов, а тем, что ДО ее построения он сформулировал ПЕРИОДИЧЕСКИЙ ЗАКОН изменения свойств химических элементов в зависимости от их атомной массы, по справедливости носящий его имя, чего до него не смог сделать НИКТО из его многочисленных предшественников «по цеху». 


\section{О формулировке Периодического Закона Д.И. Менделеева}

В марте 1869 г. Дмитрий Иванович Менделеев представил Русскому химическому обществу (PХO) периодический закон химических элементов, изложенный в семи основных положениях [9]:

1. Элементы, расположенные по возрастанию их атомного веса, представляют явственную периодичность свойств;

2. Сходные по свойствам элементы имеют или близкие атомные веса (Ir, Pt, Os), или последовательно и однообразно увеличивающиеся (K, Rb, $C s)$;

3. Сопоставление элементов или их групп по величине атомного веса отвечает их т.н. атомности;

4. Элементы с малыми атомными весами имеют наиболее резко выраженные свойства, поэтому они являются типическими элементами;

5. Величина атомного веса определяет характер элемента;

6. Следует ожидать открытия ещё многих неизвестных элементов, например, сходных с Al или $\mathrm{Si}$, с паем (атомной массой) 65-75;

7. Величина атомного веса элемента может быть иногда исправлена, если знать аналоги данного элемента. Так, пай Те должен быть не 128, a $123-126$.

Статья [9] вышла в марте 1869 г., но уже спустя всего два месяца (!!) после этого в одном из ведущих научных журналов того времени "Zeitschrift fur Chemie" был опубликован краткий реферат этой самой статьи [10]. В том же 1869 г. вышло в свет первое издание учебника «Основы химии» [8], в котором приведена ПЕРВАЯ система химических элементов Д.И. Менделеева, состав- ленная как раз с использованием только что приведенных положений (Рис. 1).

Эта табличная система, как можно видеть, была еще весьма несовершенна и представляла собой скорее набросок, нежели что-то цельное. Тем не менее именно на ее основе в конце 1870 г. Менделеев представил в РХО доклад «Естественная система элементов и применение её к указанию свойств неоткрытых элементов», в которых предсказал свойства неоткрытых ещё элементов - аналогов бора, алюминия и кремния (соответственно экабор, экаалюминий и экасилищий) [1,2]. В более поздней работе «Периодическая законность химических элементов», опубликованной в 1871 г., он дал следующую более емкую формулировку Периодического закона: "Свойства элементов, а потому и свойства образуемых ими простых и сложных тел стоят в периодической зависимости от атомного веса» [1, 2]. [Заметим, что в этих двух системах отсутствовали инертные газы, которые в то время еще не были известны химической науке (первый из них - аргон был открыт лишь в 1894 г.), и даже гений Д.И. Менделеева не смог предсказать их существование. Они появились в его таблице лишь в начале XX века, когда по предложению бельгийского химика А. Эрреры и английского химика У. Рамзая, и, что весьма симптоматично, по согласованию (!) с Д.И. Менделеевым в 1900 г. в Периодическую систему была введена нулевая группа химических элементов [11]].

Д.И. Менделеев заложил в свое определение термин «атомная масса», поскольку в то время таковая была фактически единственной характеристикой атомов, которую можно было определить экспериментально. Однако довольно скоро он сам же и обнаружил, что при использовании этого

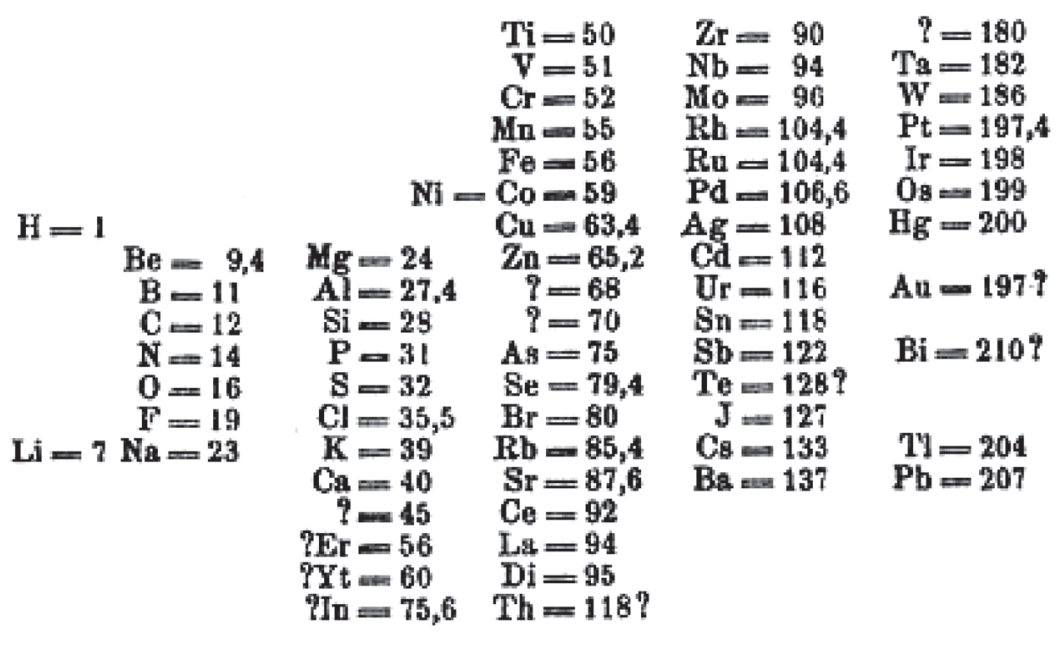

Рис. 1. Первоначальная табличная система химических элементов, составленная Д.И. Менделеевым 
параметра в отдельных случаях имеет место отклонение от найденной им закономерности (так, Те ему пришлось поставить впереди J, хотя атомная масса последнего была меньшей). После введения в научный оборот понятия «заряд ядра (нуклида)» в определение Периодического Закона было внесено уточнение и в современных учебниках химии он трактуется несколько иначе, а именно «Свойства простых веществ, а также свойства и формы соединений элементов находятся в периодической зависимости от заряда ядра атомов элементов» [12]. Однако и ТАКОЕ определение нуждается в уточнении - причем по меньшей мере по двум причинам. С одной стороны, под периодической зависимостью в математике вообще-то понимается такая функция $f(x)$, для которой можно указать как минимум одно значение параметра $T$, для которого $f(x+T)=f(x)$ при любом значении х (классическими примерами таких зависимостей являются т.н. тригонометрические функции). Применительно к нашему случаю это означает, что для соответствия вышеуказанному определению периодической зависимости количественного параметра $p$, характеризующего какое-то конкретное свойство химического элемента, зависящее от заряда ядра $Z$, должно иметь место равенство $p(Z)=p(Z+T)$, чего на самом деле не имеет места ни для одного из известных их свойств. Зависимости $p(Z)$ могут быть в той или иной степени близкими к периодическим зависимостям, но не строго периодическими, как это требуется согласно определению. С другой стороны, существуют и такие свойства химических элементов, которые не находятся даже в близкой к периодической зависимости от величины $Z$; примером может служить, в частности, усредненная атомная масса конкретного химического элемента, которая монотонно возрастает с ростом величины $Z$. Вот почему наиболее точной представляется следующая формулировка Периодического Закона Д.И. Менделеева: «Большинство свойств химических элементов и их соединений находится в близкой к периодической зависимости от заряда соответствующих им нуклидов (атомных ядер)».

Заканчивая этот параграф, отметим следующее важное обстоятельство: Д.И. Менделеев вскрыл ФАКТ закономерного изменения свойств химических элементов с ростом атомных масс и сформулировал Периодический закон, но не смог объяснить ПРИЧИНУ периодичности, заложенной в его формулировке. Что, в общем-то, неудивительно, если учесть, что, во-первых, собственно этой проблематикой он занимался отнюдь не всю жизнь (по некоторым сведениям - не более пяти лет), во-вторых, он - как это не удивительно - не был до конца уверен даже... в самом существовании атомов (извест- но его изречение «в атоме много простоты, но нет наглядности»), а в-третьих - и это главное - в его время еще не было той основополагающей теории строения атома, без которой понять эту причину просто не представляется возможным. Такая теория была создана лишь в двадцатых годах XX столетия, спустя почти двадцать лет после кончины творца Периодического Закона...

\section{Ранние варианты Периодической системы химических элементов}

С Периодическим Законом Д.И. Менделеева неразрывно связаны весьма многочисленные поПЫТКИ еГО КОЛИЧЕСТВЕННОЙ ИНТЕРПРЕТАЦИИ. Дело в том, что в отличие от большинства законов физики (а Периодический Закон, как уже упоминалось в преамбуле данной статьи - из их числа), для которых имеют место конкретные математические выражения (формулы), связывающие меж собой те или иные количественные параметры объектов, явлений или процессов (например, силу протекающего через проводник электрического тока в зависимости от напряжения и сопротивления проводника в законе Ома, силу притяжения между двумя телами в зависимости от их масс и расстояния между центрами этих масс в законе всемирного тяготения Ньютона и т.п.), для Периодического Закона такой конкретной формулы нет. Во всяком случае, такая формула, в рамках которой свойства химических элементов были бы количественно связаны с зарядом нуклида, до сих пор не найдена ни для одного из этих свойств (хотя попытки нахождения таковой и неоднократно предпринимались). В связи с этим важным обстоятельством могут быть предложены самые разнообразные варианты его интерпретации. К настоящему времени число этих вариантов измеряется уже как минимум трехзначным числом; об отдельных из них и пойдет далее речь.

Сразу же отметим три момента, связанные с расхожим среди химиков словесным штампом «Периодическая система химических элементов Д.И. Менделеева». Дело в том, что, во-первых, сам первооткрыватель Периодического Закона, насколько известно, никогда не называл свою систему «периодической». Во-вторых, в разное время был предложен целый ряд ТАКИХ вариантов системы химических элементов, основанных на Периодическом Законе, где чисто внешне усмотреть какую-либо «периодичность» едва ли возможно. А в-третьих - и это, пожалуй, главное - перу самого Дмитрия Ивановича принадлежат лишь ТРИ варианта периодической системы химических элементов, а именно тот, что уже был указан нами 


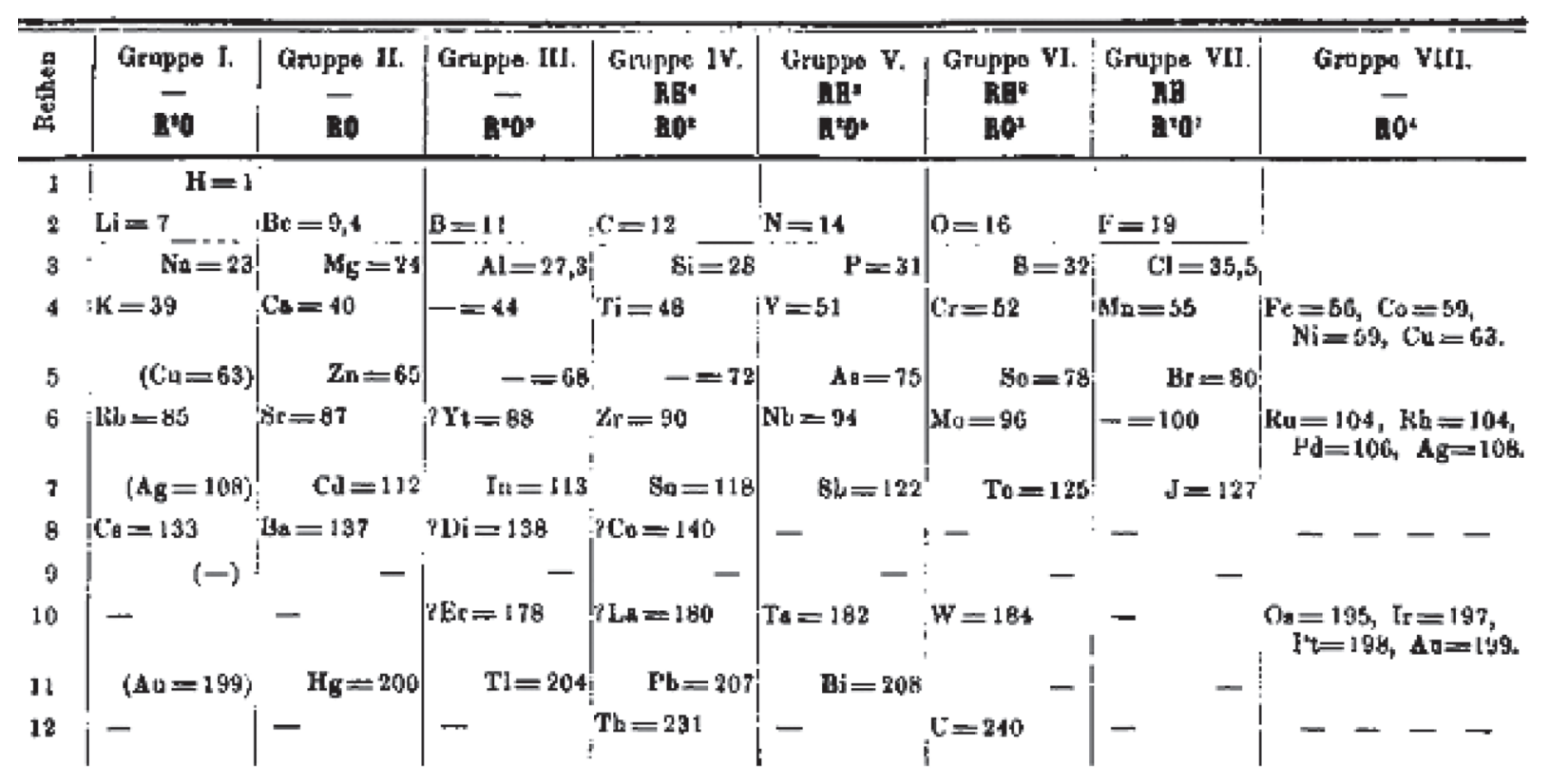

Рис. 2. Короткий вариант табличной системы химических элементов, предложенный Д.И. Менделеевым и датированный 1871 г

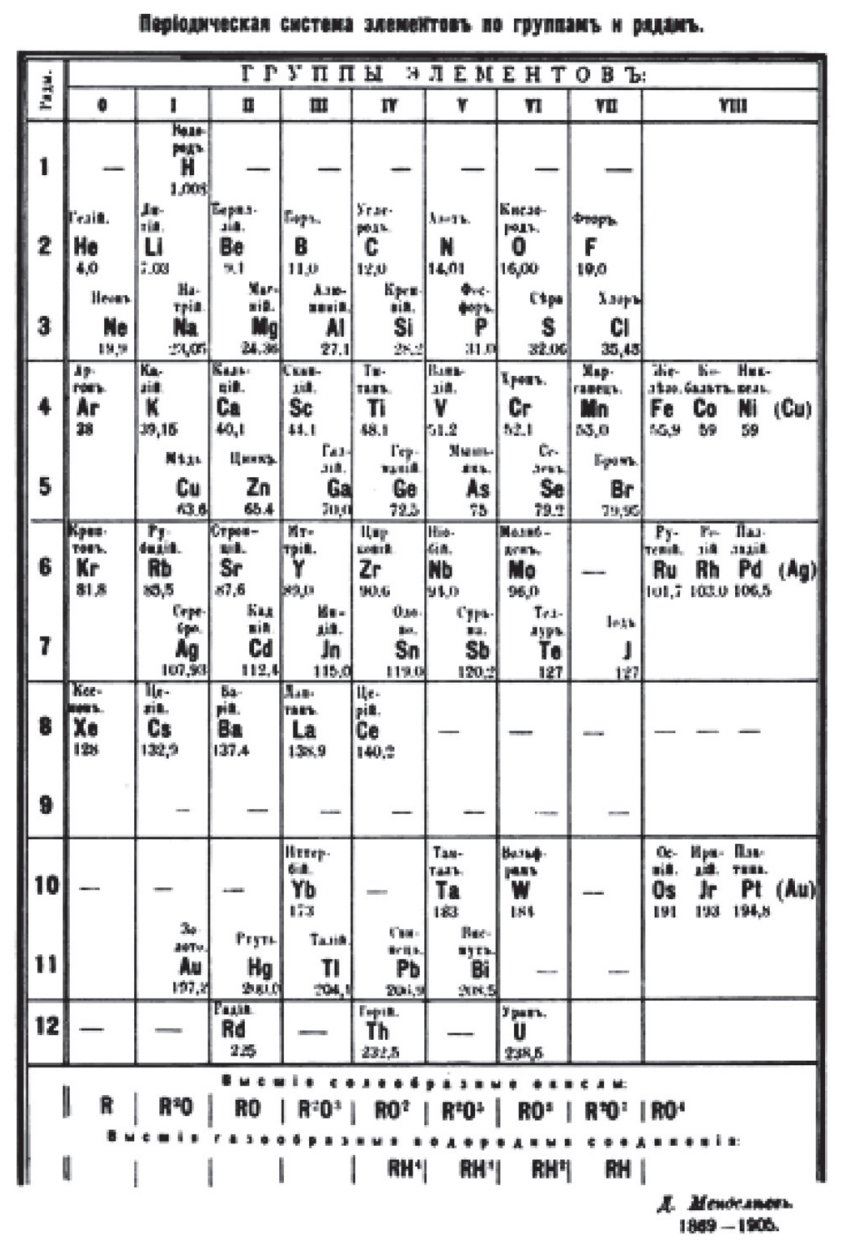

Рис. 3. Короткий вариант табличной системы химических элементов, предложенный Д.И. Менделеевым и датированный 1905 г чуть выше (Рис. 1), тот, что был приведен в его статье «Периодическая законность химических элементов» (т.н. короткий вариант) (Рис. 2), и, наконец, тот, что представлен в более позднем издании его «Основ химии» 1905 г. (Рис. 3). [В скобках заметим, что положение дел здесь несколько напоминает ситуацию с хорошо известным в математике словосочетанием «бином Ньютона», который, с одной стороны, вовсе не бином (т.е не двучлен), с другой стороны, связанные с ним многочлены были известны и до Ньютона]. С учетом только что сказанного этот самый штамп следует признать, мягко говоря, не вполне корректным (в отличие от штампа «Периодический Закон химических элементов Д.И. Менделеева», где упоминание его имени полностью оправдано, пусть даже формулировка Закона так или иначе уточнялась со временем). Этот «короткий» вариант впоследствии подвергся многочисленным дополнениям и совершенствованием как по существу, так и по дизайну; ныне он известен под названием короткопериодического варианта Периодической системы химических элементов Д.И. Менделеева. Одно из его многочисленных современных изображений представлено на Рис. 4. Как нетрудно заметить, в нем восемь групп и семь периодов, причем последний, седьмой, был завершен лишь совсем недавно [1316]. Заметим в связи с этим, что последний элемент из этого самого последнего периода - оганессон $\mathrm{Og}$ - назван в честь ДЕЙСТВУЮЩЕГО на момент его открытия российского физика Ю.Ц. Оганесяна 


\begin{tabular}{|c|c|c|c|c|c|c|c|c|c|c|c|c|c|c|}
\hline \multicolumn{15}{|c|}{ ГРУППЫ ХИМИЧЕСКИХ ЭЛЕМЕНТОВ } \\
\hline & I & II & III & IV & $\mathbf{V}$ & VI & VII & \multicolumn{3}{|c|}{ VIII } & & & & \\
\hline 1 & ${ }^{1} \mathbf{H}$ & & & & & & $\left({ }^{1} \mathbf{H}\right)$ & ${ }^{2} \mathrm{He}$ & & & & & & \\
\hline 2 & ${ }^{3} \mathrm{Li}$ & ${ }^{4} \mathrm{Be}$ & ${ }^{5} \mathrm{~B}$ & ${ }^{6} \mathrm{C}$ & ${ }^{7} \mathbf{N}$ & ${ }^{8} \mathrm{O}$ & ${ }^{9} \mathbf{F}$ & ${ }^{10} \mathrm{Ne}$ & & & & & & \\
\hline 3 & ${ }^{11} \mathrm{Na}$ & ${ }^{12} \mathrm{Mg}$ & ${ }^{13} \mathrm{Al}$ & ${ }^{14} \mathrm{Si}$ & ${ }^{15} \mathbf{P}$ & ${ }^{16} \mathrm{~S}$ & ${ }^{17} \mathrm{Cl}$ & ${ }^{18} \mathrm{Ar}$ & & & & & & \\
\hline \multirow{2}{*}{4} & ${ }^{19} \mathbf{K}$ & ${ }^{20} \mathrm{Ca}$ & ${ }^{21} \mathrm{Sc}$ & ${ }^{22} \mathrm{Ti}$ & ${ }^{23} \mathrm{~V}$ & ${ }^{24} \mathrm{Cr}$ & ${ }^{25} \mathrm{Mn}$ & ${ }^{26} \mathrm{Fe}$ & ${ }^{27} \mathrm{Co}$ & ${ }^{28} \mathrm{Ni}$ & & & & \\
\hline & ${ }^{29} \mathrm{Cu}$ & ${ }^{30} \mathbf{Z n}$ & ${ }^{31} \mathrm{Ga}$ & ${ }^{32} \mathrm{Ge}$ & ${ }^{33} \mathrm{As}$ & ${ }^{34} \mathrm{Se}$ & ${ }^{35} \mathrm{Br}$ & ${ }^{36} \mathbf{K r}$ & & & & & & \\
\hline \multirow{2}{*}{5} & ${ }^{37} \mathbf{R b}$ & ${ }^{38} \mathrm{Sr}$ & ${ }^{39} \mathbf{Y}$ & ${ }^{40} \mathrm{Zr}$ & ${ }^{41} \mathbf{N b}$ & ${ }^{42} \mathrm{Mo}$ & ${ }^{43} \mathrm{Tc}$ & ${ }^{44} \mathbf{R u}$ & ${ }^{45} \mathbf{R h}$ & ${ }^{46} \mathrm{Pd}$ & & & & \\
\hline & ${ }^{47} \mathrm{Ag}$ & ${ }^{48} \mathrm{Gd}$ & ${ }^{49}$ In & ${ }^{50} \mathrm{Sn}$ & ${ }^{51} \mathrm{Sb}$ & ${ }^{52} \mathrm{Te}$ & ${ }^{53} \mathrm{~J}$ & ${ }^{54} \mathrm{Xe}$ & & & & & & \\
\hline \multirow{2}{*}{6} & ${ }^{55} \mathrm{Cs}$ & ${ }^{56} \mathbf{B a}$ & ${ }^{57} \mathrm{La}$ & ${ }^{72} \mathrm{Hf}$ & ${ }^{73} \mathrm{Ta}$ & ${ }^{74} \mathrm{~W}$ & ${ }^{75} \operatorname{Re}$ & ${ }^{76} \mathrm{Os}$ & ${ }^{77} \mathbf{I r}$ & ${ }^{78} \mathrm{Pt}$ & & & & \\
\hline & ${ }^{79} \mathrm{Au}$ & ${ }^{80} \mathrm{Hg}$ & ${ }^{81} \mathrm{Tl}$ & ${ }^{82} \mathrm{~Pb}$ & ${ }^{83} \mathrm{Bi}$ & ${ }^{84} \mathrm{Po}$ & ${ }^{85}$ At & ${ }^{86} \mathbf{R n}$ & & & & & & \\
\hline \multirow{2}{*}{7} & ${ }^{87} \mathrm{Fr}$ & ${ }^{88} \mathbf{R a}$ & ${ }^{89} \mathrm{Ac}$ & ${ }^{104} \mathrm{Rf}$ & ${ }^{105} \mathrm{Db}$ & ${ }^{106} \mathrm{Sg}$ & ${ }^{107} \mathrm{Bh}$ & ${ }^{108} \mathrm{Hs}$ & ${ }^{109} \mathrm{Mt}$ & ${ }^{110} \mathrm{Ds}$ & & & & \\
\hline & ${ }^{111} \mathbf{R g}$ & ${ }^{112} \mathrm{Cn}$ & ${ }^{113} \mathrm{Nh}$ & ${ }^{114} \mathrm{FI}$ & ${ }^{115} \mathrm{Mc}$ & ${ }^{116} \mathrm{Lv}$ & ${ }^{117} \mathrm{Ts}$ & ${ }^{118} \mathrm{Og}$ & & & & & & \\
\hline \multicolumn{15}{|c|}{ ЛАНТАНОИДЫ } \\
\hline & ${ }^{58} \mathrm{Ce}$ & ${ }^{59} \mathrm{Pr}$ & ${ }^{60} \mathrm{Nd}$ & ${ }^{61} \mathbf{P m}$ & ${ }^{62} \mathrm{Sm}$ & ${ }^{63} \mathrm{Eu}$ & ${ }^{64} \mathrm{Gd}$ & ${ }^{65} \mathrm{~Tb}$ & ${ }^{66} \mathrm{Dy}$ & ${ }^{67} \mathrm{Ho}_{0}$ & ${ }^{68} \mathbf{E r}$ & ${ }^{69} \mathrm{Tm}$ & ${ }^{70} \mathrm{Yb}$ & ${ }^{71} \mathrm{Lu}$ \\
\hline \multicolumn{15}{|c|}{ АКТИНОИДЫ } \\
\hline & ${ }^{90} \mathrm{Th}$ & ${ }^{91} \mathrm{~Pa}$ & ${ }^{92} \mathrm{U}$ & ${ }^{93} \mathrm{~Np}$ & ${ }^{94} \mathrm{Pu}$ & ${ }^{95} \mathrm{Am}$ & ${ }^{96} \mathrm{Cm}$ & ${ }^{97} \mathrm{Bk}$ & ${ }^{98} \mathrm{Cf}$ & ${ }^{99} \mathrm{Es}$ & ${ }^{100} \mathrm{Fm}$ & ${ }^{101} \mathrm{Md}$ & ${ }^{102} \mathrm{No}$ & ${ }^{103} \mathrm{Lr}$ \\
\hline
\end{tabular}

Рис. 4. Современный «короткопериодический» вариант Периодической системы химических элементов. Надстрочными индексами слева указаны заряды нуклидов соответствующих атомов

(что произошло едва ли не впервые в истории открытия химических элементов!).

Следующим по хронологии вариантом Периодической системы химических элементов оказывается т.н. «длиннопериодический» вариант, авторство которого принадлежит другому великому ученому-химику, а именно А. Вернеру (Швейцария) (хотя есть некоторые указания на то, что нечто подобное предлагал в свое время и Менделе- ев). Его имя давно и хорошо известно любому специалисту в области неорганической и координационной химии, поскольку именно он является автором координационной теории, основные положения которой сохраняют свою силу и в настоящее время, спустя более 125 лет с момента ее создания (1893 г.), однако он «отметился» и на ниве систематики химических элементов. К созданию «длиннопериодического» варианта А. Вернера, возможно,

\begin{tabular}{|c|c|c|c|c|c|c|c|c|c|c|c|c|c|c|c|c|c|c|}
\hline \multicolumn{19}{|c|}{ ГРУППЫ ХИМИЧЕСКИХ ЭЛЕМЕНТОВ } \\
\hline & 1 & 2 & 3 & 4 & 5 & 6 & 7 & 8 & 9 & 10 & 11 & 12 & 13 & 14 & 15 & 16 & 17 & 18 \\
\hline 1 & ${ }^{1} \mathbf{H}$ & & & & & & & & & & & & & & & & & ${ }^{2} \mathrm{He}$ \\
\hline 2 & ${ }^{3} \mathbf{L i}$ & ${ }^{4} \mathrm{Be}$ & & & & & & & & & & & ${ }^{5} \mathrm{~B}$ & ${ }^{6} \mathrm{C}$ & ${ }^{7} \mathbf{N}$ & ${ }^{8} \mathrm{O}$ & ${ }^{9} \mathbf{F}$ & ${ }^{10} \mathrm{Ne}$ \\
\hline 3 & ${ }^{11} \mathrm{Na}$ & ${ }^{12} \mathrm{Mg}$ & & & & & & & & & & & ${ }^{13} \mathrm{Al}$ & ${ }^{14} \mathrm{Si}$ & ${ }^{15} \mathrm{P}$ & ${ }^{16} \mathrm{~S}$ & ${ }^{17} \mathrm{Cl}$ & ${ }^{18} \mathrm{Ar}$ \\
\hline 4 & ${ }^{19} \mathbf{K}$ & ${ }^{20} \mathrm{Ca}$ & ${ }^{21} \mathrm{Sc}$ & ${ }^{22} \mathbf{T i}$ & ${ }^{23} \mathrm{~V}$ & ${ }^{24} \mathrm{Cr}$ & ${ }^{25} \mathrm{Mn}$ & ${ }^{26} \mathrm{Fe}$ & ${ }^{27} \mathrm{Co}$ & ${ }^{28} \mathrm{Ni}$ & ${ }^{29} \mathrm{Cu}$ & ${ }^{30} \mathbf{Z n}$ & ${ }^{31} \mathrm{Ga}$ & ${ }^{32} \mathrm{Ge}$ & ${ }^{33} \mathrm{As}$ & ${ }^{34} \mathrm{Se}$ & ${ }^{35} \mathrm{Br}$ & ${ }^{36} \mathbf{K r}$ \\
\hline 5 & ${ }^{37} \mathbf{R b}$ & ${ }^{38} \mathrm{Sr}$ & ${ }^{39} \mathbf{Y}$ & ${ }^{40} \mathrm{Zr}$ & ${ }^{41} \mathrm{Nb}$ & ${ }^{42} \mathrm{Mo}$ & ${ }^{43} \mathrm{Tc}$ & ${ }^{44} \mathbf{R u}$ & ${ }^{45} \mathrm{Rh}$ & ${ }^{46} \mathrm{Pd}$ & ${ }^{47} \mathrm{Ag}$ & ${ }^{48} \mathbf{G d}$ & ${ }^{49} \mathrm{In}$ & ${ }^{510} \mathrm{Sn}$ & ${ }^{51} \mathrm{Sb}$ & ${ }^{52} \mathrm{Te}$ & ${ }^{53} \mathbf{J}$ & ${ }^{54} \mathrm{Xe}$ \\
\hline 6 & ${ }^{55} \mathrm{Cs}$ & ${ }^{56} \mathrm{Ba}$ & ${ }^{57} \mathrm{La}$ & ${ }^{72} \mathbf{H f}$ & ${ }^{73} \mathrm{Ta}$ & ${ }^{74} \mathrm{~W}$ & ${ }^{75} \mathbf{R e}$ & ${ }^{76} \mathrm{Os}$ & ${ }^{77} \mathbf{I r}$ & ${ }^{78} \mathrm{Pt}$ & ${ }^{79} \mathrm{Au}$ & ${ }^{80} \mathbf{H g}$ & ${ }^{81} \mathrm{Tl}$ & ${ }^{82} \mathrm{~Pb}$ & ${ }^{83} \mathrm{Bi}$ & ${ }^{84} \mathrm{Po}$ & ${ }^{85} \mathrm{At}$ & ${ }^{86} \mathbf{R n}$ \\
\hline 7 & ${ }^{87} \mathbf{F r}$ & ${ }^{88} \mathbf{R a}$ & ${ }^{89} \mathrm{Ac}$ & ${ }^{104} \mathbf{R f}$ & ${ }^{105} \mathrm{Db}$ & ${ }^{106} \mathrm{Sg}$ & ${ }^{107} \mathbf{B h}$ & ${ }^{108} \mathrm{Hs}$ & ${ }^{109} \mathrm{Mt}$ & ${ }^{110} \mathrm{Ds}$ & ${ }^{111} \mathrm{Rg}$ & ${ }^{112} \mathrm{Cn}$ & ${ }^{113} \mathrm{Nh}$ & ${ }^{114} \mathrm{FI}$ & ${ }^{115} \mathbf{M c}$ & ${ }^{116} \mathrm{Lv}$ & ${ }^{117} \mathrm{Ts}$ & ${ }^{118} \mathrm{Og}$ \\
\hline \multicolumn{19}{|c|}{ ЛАНТАНОИДЫ } \\
\hline & & & ${ }^{58} \mathrm{Ce}$ & ${ }^{59} \mathrm{Pr}$ & ${ }^{60} \mathrm{Nd}$ & ${ }^{61} \mathrm{Pm}$ & ${ }^{62} \mathrm{Sm}$ & ${ }^{63} \mathbf{E u}$ & ${ }^{64} \mathrm{Gd}$ & ${ }^{65} \mathrm{~Tb}$ & ${ }^{66} \mathrm{Dy}$ & ${ }^{67} \mathrm{Ho}$ & ${ }^{68} \mathbf{E r}$ & ${ }^{69} \mathrm{Tm}$ & ${ }^{70} \mathbf{Y b}$ & ${ }^{71} \mathbf{L u}$ & & \\
\hline \multicolumn{19}{|c|}{ АКТИНОИДЫ } \\
\hline & & & ${ }^{90} \mathrm{Th}$ & ${ }^{91} \mathrm{~Pa}$ & ${ }^{92} \mathrm{U}$ & ${ }^{93} \mathbf{N p}$ & ${ }^{94} \mathrm{Pu}$ & ${ }^{95} \mathrm{Am}$ & ${ }^{96} \mathrm{Cm}$ & ${ }^{97} \mathrm{Bk}$ & ${ }^{98} \mathrm{Cf}$ & ${ }^{99}$ Es & ${ }^{100} \mathrm{Fm}$ & ${ }^{101} \mathbf{M d}{ }^{1}$ & ${ }^{102} \mathrm{No}^{1}$ & ${ }^{103} \mathrm{Lr}$ & & \\
\hline
\end{tabular}

Рис. 5. Современный «длиннопериодический» вариант Периодической системы химических элементов. Надстрочными индексами слева указаны заряды нуклидов соответствующих атомов 


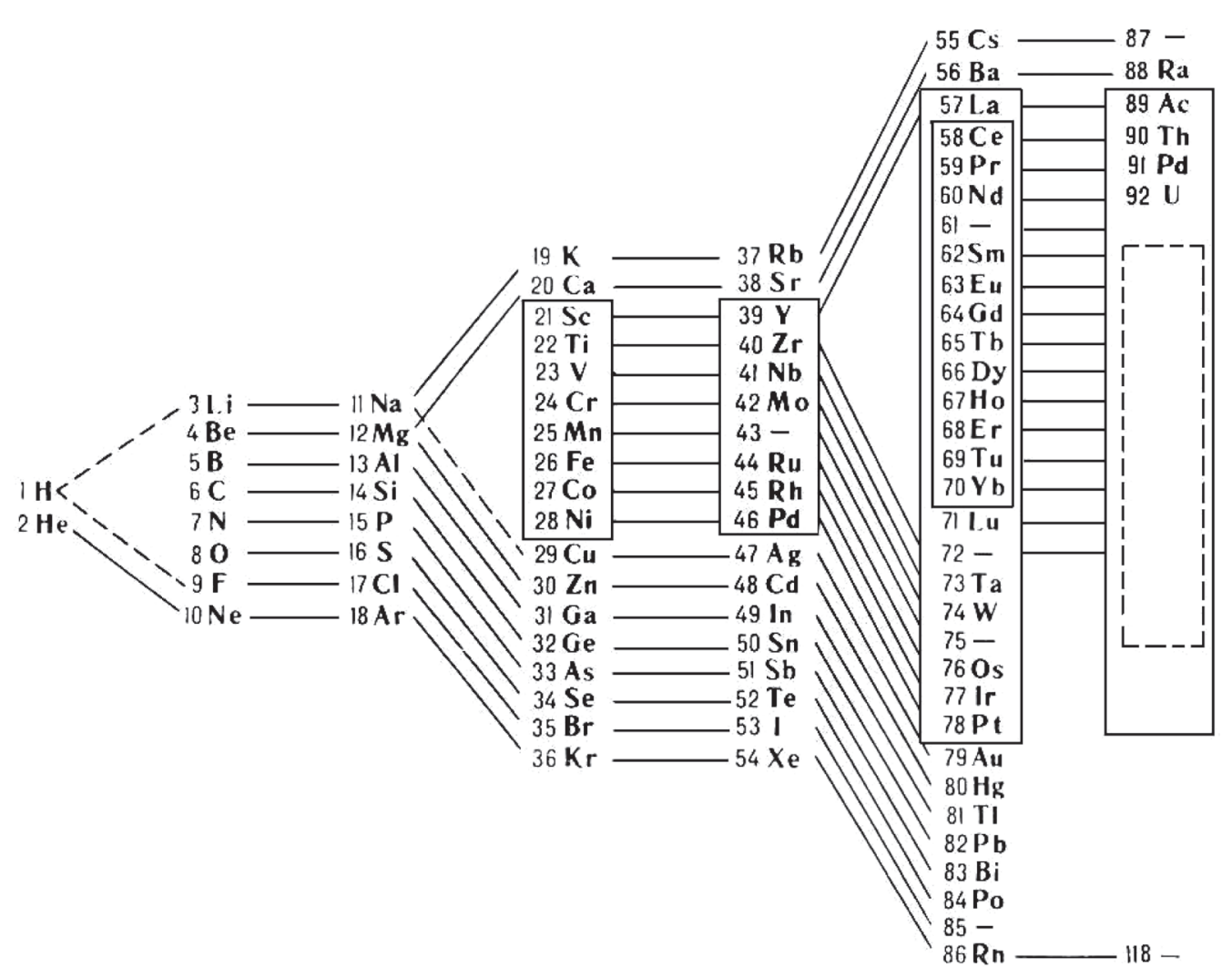

Рис. 6. «Лестничный» вариант Периодической системы химических элементов. Индексами слева указаны заряды нуклидов соответствующих им атомов. (Символы элементов №№ 43, 61, 72, 75, 85, 87 в таблице не указаны, поскольку на момент создания данной таблицы они еще не были открыты)

подвигло то обстоятельство, что в варианте «короткопериодическом» первые три периода оказывались, так сказать, «однорядными», тогда как все последующие - «двухрядными». В результате получился тоже табличный вариант, но сама таблица как бы «раздалась вширь», и групп химических элементов стало не девять, как было в таблице самого Менделеева, а вдвое большее их число (Рис. 5). Заметим в связи с этим, что этот вариант получил весьма широкое распространение среди химиков - во всяком случае, именно он был рекомендован в свое время для использования Международным Союзом по чистой и прикладной химии (IUPAC) и принят ныне во многих странах мира. Но не в России: наши исследователи, преподаватели химии, да и студенты предпочитают вариант «короткопериодический» (т.е. потомок собственно «менделеевского»). Вряд ли это интересное обстоятельство хоть как-то связано с тем, что «Менделеев - это наш, а Вернер - не наш»: скорее всего, причина предпочтения «короткопериодического» варианта «длиннопериодическому» в нашей стране коренится в том, что он более компактный, да и номера групп в нем имеют более четкое толкование, нежели в «длиннопериодическом». Впрочем, как в том, так и в другом вариантах часть эле- ментов все равно оказываются за пределами собственно таблицы... Еще одним из ранних вариантов интерпретации Периодического Закона, который заслуживает упоминания в данном параграфе, является т.н. «лестничный», предложенный в 1882 г. англичанином Т. Бэйли и затем в 1921 г. усовершенствованный другим великим ученым, а именно Н. Бором, представленный на Рис. 6.

Исходя из всего сказанного в данном параграфе, следует признать, что упоминание имени Д.И. Менделеева в каких-либо иных вариантах интерпретации Периодического Закона, за исключением «короткопериодического» и - с оговорками - «длиннопериодического», является не вполне оправданным.

\section{Другие варианты Периодической системы химических элементов}

Хорошо известна следующая примечательная фраза Д.И. Менделеева по поводу открытой им закономерности: «Периодическому Закону не угрожает разрушение, а лишь надстройка обешаетcя». Под этой самой «надстройкой» он, несомненно, подразумевал различные варианты Периодической системы химических элементов, которые появятся 


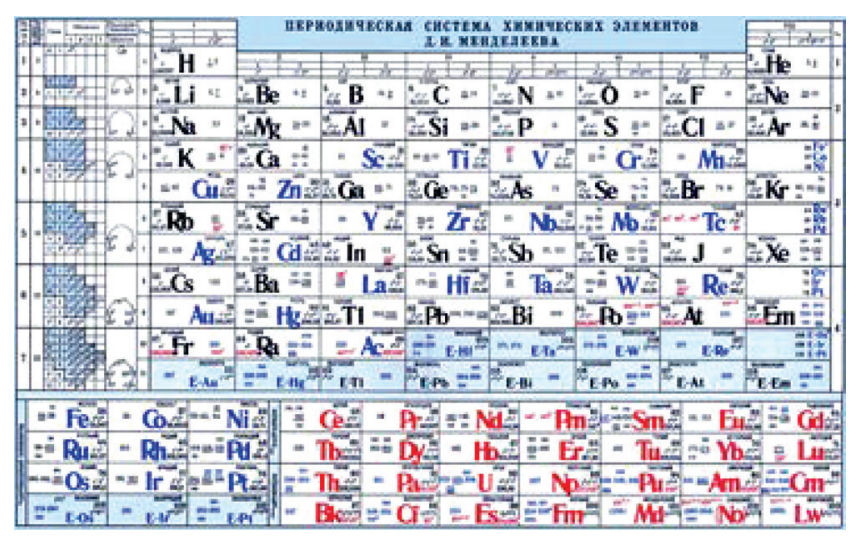

Рис. 7. Нетрадиционная версия «короткопериодического» варианта системы химических элементов в будущем. И действительно, за 150 лет, прошедших с момента появления Периодического Закона, в разное время было предложено множество самых различных вариантов интерпретации данного закона, число которых по разным оценкам составляет более 500, свыше 400 из которых - табличные, остальные же остальное - различные геометрические фигуры, математические кривые и т.п. $[17,18]$. (Тут, впрочем, необходимо уточнить, что эти 400 с лишним табличных вариантов учитывают и дизайнерскую сторону дела - к примеру, как «короткопериодический», так и «длиннопериодический» вариант представлен целым рядом таблиц, различающихся меж собой, как правило, лишь раскраской «элементных» клеток, наличием или отсутствием рельефности и т.Д. и т.п.,

\begin{tabular}{|c|c|c|c|c|c|c|c|c|c|c|c|c|c|c|c|c|c|c|c|c|c|c|c|c|c|c|c|c|c|c|c|}
\hline \multirow{2}{*}{ 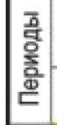 } & \multicolumn{31}{|c|}{ Группы } \\
\hline & 7 & 8 & 1 & 2 & 3 & 4 & 5 & 6 & 7 & 8 & 1 & 2 & 3 & 4 & 5 & 6 & 7 & 8 & 1 & 23 & \begin{tabular}{l|l}
3 & 4
\end{tabular} & \begin{tabular}{l|l}
45 \\
\end{tabular} & 6 & 7 & 8 & 12 & $\begin{array}{ll}2 & 3\end{array}$ & 3 & 4 & 5 & \\
\hline I & $\mathrm{H}$ & $\mathrm{He}$ & Li & \begin{tabular}{|c|}
$\mathrm{Be}$ \\
4
\end{tabular} & & & & & & & & & & & & & & & & & & & & & & & & & & $\overline{\mathrm{N}}$ & \\
\hline "I & $F$ & $\mathrm{Ne}$ & $\mathrm{Na}$ & $\mathrm{Mg}$ & & & & & & & & & & & & & & & & & & & & & & & & & & P & \\
\hline & & & 11 & 12 & & & & & & & & & & & & & & & & & & & & & & & & & & 15 & \\
\hline 措 & $\mathrm{Cl}$ & Ar & K & $\mathrm{Ca}$ & $\mathrm{Sc}$ & $\mathrm{Ti}$ & V & $\mathrm{Cr}$ & $\operatorname{Mn} F$ & $\mathrm{Fe}$ & & & & & & & & $C_{0}$ & & & & & & & Ni C & $\mathrm{Cu} \mathrm{ZI}$ & $\mathrm{Zn} G$ & $\mathrm{Ga} \mathrm{C}$ & $\mathrm{Ge} A$ & As $\$$ & \\
\hline III] & 17 & 18 & 19 & 20 & 21 & 22 & 23 & 24 & 25 & 26 & & & & & & & & 26 & & & & & & & 26 & $\begin{array}{lll}27 & 28\end{array}$ & $28 \quad 2$ & \begin{tabular}{l|l}
29 & 3
\end{tabular} & 30 & $31=$ & \\
\hline IV & $\mathrm{Br}$ & $\mathrm{Kr}$ & $\mathrm{Rb}$ & $\mathrm{Sr}$ & $Y$ & $\mathrm{Zr}$ & $\mathrm{Nb}$ & Mo & Tc F & $\mathrm{Ru}$ & La & $\mathrm{Ce}$ & $\operatorname{Pr}$ & $\mathrm{Nd} F$ & $\mathrm{Pm}$ & $\mathrm{Sm} \mathrm{E}$ & Eu & $\mathrm{Rh} 1$ & $\mathrm{~b}[\mathrm{c}$ & \begin{tabular}{l|l} 
\\
\end{tabular} & $\begin{array}{l}H_{0} \\
\text { E }\end{array}$ & \begin{tabular}{l|l}
$\mathrm{T}$ & $\mathrm{Tm}$
\end{tabular} & $\mathrm{Yb}$ & Lu F & $\mathrm{Pd} / \mathrm{A}$ & $\mathrm{Ag} \mathrm{C}$ & $\mathrm{Cd}$ In & $\ln S$ & Sn $S$ & $\begin{array}{ll}\mathrm{Sb} & T\end{array}$ & \\
\hline iv & 33 & 34 & 35 & 36 & 37 & 38 & 39 & 40 & 41 & 42 & 43 & 44 & 45 & 46 & 47 & 48 & 49 & 50 & 51 & \begin{tabular}{l|l}
52 & 5 \\
\end{tabular} & \begin{tabular}{l|l}
53 & 54 \\
\end{tabular} & 5455 & 56 & 57 & \begin{tabular}{l|l}
58 & 5 \\
\end{tabular} & \begin{tabular}{l|l}
59 & 60
\end{tabular} & \begin{tabular}{l|l}
60 & 8 \\
\end{tabular} & \begin{tabular}{l|l}
61 & 6 \\
\end{tabular} & 62 & $\begin{array}{ll}63 & 6\end{array}$ & \\
\hline y & 1 & $x_{e}$ & $\mathrm{Cs}$ & $\mathrm{Ba}$ & Gd & $\mathrm{Hf}$ & $\mathrm{Ta}$ & w & $\operatorname{Re}$ & Os & $\mathrm{Ac}$ & Th & $\mathrm{Pa}$ & U & Np & $\mathrm{Pu} A$ & $\mathrm{Am}$ & Ir & $3 k$ & $\mathrm{Cf} \mathrm{E}$ & Es Fm & $\mathrm{m} M \mathrm{~d}$ & No & Lr & Pt A & $\mathrm{Au}$ & $\mathrm{Hg} \mathrm{T}$ & $\mathrm{TI} P$ & $\mathrm{~Pb}$ & $\mathrm{Bi} F$ & \\
\hline$v$ & 65 & 66 & 67 & 68 & 69 & 70 & 71 & 72 & 73 & 74 & 75 & 76 & 77 & 78 & 78 & 80 & 81 & 82 & 33 & \begin{tabular}{l|l}
84 & 85
\end{tabular} & \begin{tabular}{l|l}
85 & 86
\end{tabular} & $\begin{array}{lll}66 & 87\end{array}$ & 88 & 80 & $90: 8$ & $\begin{array}{lll}91 & 82\end{array}$ & \begin{tabular}{l|l}
92 & 9
\end{tabular} & 938 & \begin{tabular}{l|l}
94 & 8
\end{tabular} & $\begin{array}{l}95 \\
\mathrm{~s}\end{array}$ & \\
\hline & At & $\mathrm{Rn}$ & $\mathrm{Fr}$ & $\mathrm{Ra}$ & $\mathrm{Cm}$ & Ku & $\mathrm{Db}$ & - & - & $=$ & & & & & & & & - & & & & & & & & & $-\quad-$ & $=$ & & - & \\
\hline $\mathrm{v}$ & 97 & 98 & 99 & 100 & 101 & 102 & 103 & 104 & 105 & 108 & & & & & & & & 106 & & & & & & & $106 \mid 1$ & $107 \quad 10$ & \begin{tabular}{l|l|l}
108 & 10
\end{tabular} & $109 / 1$ & 110 & 1111 & \\
\hline vil & $\mid \begin{array}{c}- \\
113\end{array}$ & - & $\begin{array}{c}- \\
115\end{array}$ & $\begin{array}{c}- \\
116\end{array}$ & & & & & & & & & & & & & & & & & & & & & & & & 117 & & (19. & \\
\hline VIII & $\begin{array}{c}- \\
121\end{array}$ & $\begin{array}{c}- \\
122\end{array}$ & $\begin{array}{c}- \\
123\end{array}$ & & & & & & & & & & & & & & & & & & & & & & & & & \begin{tabular}{l|l}
- & -125 \\
125
\end{tabular} & & $\begin{array}{l}- \\
127\end{array}$ & 28 \\
\hline
\end{tabular}

Рис. 8. Нетрадиционная версия «супердлиннопериодического» варианта системы химических элементов с т.н. группами химического подобия $[18,19]$

\begin{tabular}{|c|c|c|c|c|c|c|c|c|c|c|c|c|c|c|c|c|c|c|c|c|c|c|c|c|c|c|c|c|c|c|c|c|}
\hline 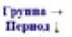 & \multicolumn{15}{|c|}{ เ11 } & $\mathrm{nu}$ & $\mathrm{N}_{\mathrm{B}}$ & $\mathrm{VIB}$ & vin & \multicolumn{3}{|c|}{ vแแs } & $m$ & min & III & iva & $\mathrm{w}$ & vis & $\mathrm{swn}$ & $\operatorname{vim}$ & in & in \\
\hline 1 & & & & & & & & & & & & & & & & & & & & & & & & & & & & & $\begin{array}{l}1 \\
\text { H }\end{array}$ & $\stackrel{2}{\mathrm{He}}$ & $\begin{array}{l}3 \\
\text { Li. }\end{array}$ & $\underset{B \mathrm{Be}}{4}$ \\
\hline 2 & & & & & & & & & & & & & & & & & & & & & & & & & $\begin{array}{l}5 \\
\text { B }\end{array}$ & $\begin{array}{l}6 \\
\mathrm{C}\end{array}$ & $\frac{7}{x}$ & $\begin{array}{l}8 \\
0\end{array}$ & $\begin{array}{l}9 \\
\text { F }\end{array}$ & $\begin{array}{l}10 \\
\mathrm{Ne}\end{array}$ & $\begin{array}{l}11 \\
\mathrm{Nan}\end{array}$ & $\begin{array}{l}12 \\
\mathrm{Mg}\end{array}$ \\
\hline 3 & & & & & & & & & & & & & & & & & & & & & & & & & $\begin{array}{l}13 \\
\text { AI }\end{array}$ & $\begin{array}{l}14 \\
\mathrm{Si}\end{array}$ & $\begin{array}{c}15 \\
\mathrm{P}\end{array}$ & $\begin{array}{c}16 \\
5\end{array}$ & $\begin{array}{l}17 \\
\mathrm{C}\end{array}$ & $\begin{array}{l}18 \\
\mathrm{Ar}\end{array}$ & $\begin{array}{l}19 \\
\mathrm{~K}\end{array}$ & $\begin{array}{l}20 \\
C_{a}\end{array}$ \\
\hline 4 & & & & & & & & & & & & & & & $\begin{array}{l}21 \\
\mathrm{Sc}\end{array}$ & $\begin{array}{l}22 \\
\mathrm{Ti}\end{array}$ & $\begin{array}{l}23 \\
\mathrm{~V}\end{array}$ & $\begin{array}{l}24 \\
\mathrm{Cr}\end{array}$ & $\begin{array}{c}25 \\
\mathrm{Mn}\end{array}$ & $\begin{array}{l}26 \\
\text { Fe }\end{array}$ & $\begin{array}{l}27 \\
\mathrm{Co}_{0}\end{array}$ & $\begin{array}{l}28 \\
\mathrm{NI}\end{array}$ & $\begin{array}{l}29 \\
\mathrm{Cu}\end{array}$ & $\begin{array}{l}30 \\
\mathrm{Zn}\end{array}$ & $\begin{array}{l}31 \\
\text { Ga }\end{array}$ & $\begin{array}{l}32 \\
\text { Ge }\end{array}$ & $\begin{array}{l}33 \\
\text { As }\end{array}$ & $\begin{array}{l}34 \\
\mathrm{Se}\end{array}$ & $\begin{array}{l}35 \\
\mathrm{Br}\end{array}$ & $\begin{array}{l}36 \\
\mathrm{Kr}\end{array}$ & $\begin{array}{l}37 \\
\mathrm{Rb}\end{array}$ & $\begin{array}{l}38 \\
\mathrm{Sr}\end{array}$ \\
\hline 5 & & & & & & & & & & & & & & & $\begin{array}{l}39 \\
Y\end{array}$ & $\begin{array}{l}40 \\
\mathrm{Zr}\end{array}$ & $\begin{array}{l}41 \\
\mathrm{Nb}\end{array}$ & $\begin{array}{l}42 \\
\mathrm{Mo}\end{array}$ & $\begin{array}{l}43 \\
\mathrm{Te}\end{array}$ & $\begin{array}{l}44 \\
\text { Ru }\end{array}$ & $\begin{array}{l}45 \\
\text { Rh }\end{array}$ & $\begin{array}{l}46 \\
\text { Pd }\end{array}$ & $\begin{array}{l}47 \\
\mathrm{Ag}\end{array}$ & $\begin{array}{l}48 \\
\mathrm{Cd}\end{array}$ & $\begin{array}{l}49 \\
\text { In }\end{array}$ & $\begin{array}{l}50 \\
\text { Sn }\end{array}$ & $\begin{array}{l}\mathbf{5 1} \\
\mathbf{S b}\end{array}$ & $\begin{array}{l}52 \\
\text { Te }\end{array}$ & $\begin{array}{c}53 \\
\text { I }\end{array}$ & $\begin{array}{l}54 \\
\text { Xe }\end{array}$ & $\begin{array}{l}55 \\
\text { Cs }\end{array}$ & $\begin{array}{l}56 \\
\text { Ba }\end{array}$ \\
\hline 6 & $\begin{array}{l}57 \\
\text { La }\end{array}$ & $\begin{array}{l}58 \\
\text { Ce }\end{array}$ & $\begin{array}{l}59 \\
\mathrm{Pr}\end{array}$ & $\begin{array}{l}60 \\
\text { Nd }\end{array}$ & $\begin{array}{l}61 \\
\mathbf{P m}\end{array}$ & $\begin{array}{l}62 \\
\text { Sm }\end{array}$ & $\begin{array}{l}63 \\
\text { Eu }\end{array}$ & $\begin{array}{l}64 \\
\text { Gd }\end{array}$ & $\begin{array}{l}65 \\
\mathrm{~Tb}\end{array}$ & $\begin{array}{l}66 \\
\text { Dy }\end{array}$ & $\begin{array}{l}67 \\
H_{0}\end{array}$ & $\begin{array}{l}68 \\
\text { Er }\end{array}$ & $\begin{array}{l}69 \\
\mathrm{Tm}\end{array}$ & $\begin{array}{l}70 \\
\mathrm{Yb}\end{array}$ & $\begin{array}{l}71 \\
\text { Lu }\end{array}$ & $\begin{array}{l}72 \\
\text { Hff }\end{array}$ & $\begin{array}{l}73 \\
\mathrm{Ta}\end{array}$ & $\begin{array}{l}74 \\
W\end{array}$ & $\begin{array}{l}75 \\
\mathrm{Re}\end{array}$ & $\begin{array}{l}76 \\
\text { Os }\end{array}$ & $\begin{array}{l}77 \\
\text { Ir }\end{array}$ & $\begin{array}{l}78 \\
\mathrm{Pt}\end{array}$ & $\begin{array}{r}79 \\
\mathrm{Au}\end{array}$ & $\begin{array}{l}80 \\
\mathrm{Hg}\end{array}$ & $\begin{array}{l}81 \\
\text { T1 }\end{array}$ & $\begin{array}{l}\mathbf{8 2} \\
\mathrm{Pb}\end{array}$ & $\begin{array}{l}83 \\
\mathbf{B i}\end{array}$ & $\begin{array}{l}84 \\
\text { Po }\end{array}$ & $\begin{array}{l}85 \\
\text { At }\end{array}$ & $\begin{array}{l}86 \\
\text { Rn }\end{array}$ & $\begin{array}{l}87 \\
\mathrm{Fr}\end{array}$ & $\begin{array}{l}88 \\
\mathrm{R}_{\mathrm{a}}\end{array}$ \\
\hline 7 & $\begin{array}{l}89 \\
\text { Ac }\end{array}$ & $\begin{array}{l}90 \\
\text { Th }\end{array}$ & $\begin{array}{l}91 \\
\mathrm{~Pa}\end{array}$ & $\begin{array}{l}92 \\
\mathrm{U}\end{array}$ & $\mathrm{Np}_{\mathrm{p}}$ & $\mathrm{Pu}$ & Am & $\mathrm{Cm}$ & Bk & $\mathrm{Cr}$ & Es & $\begin{array}{l}100 \\
\mathrm{Fm}\end{array}$ & Md & No & $\begin{array}{l}103 \\
\text { Lr }\end{array}$ & $\begin{array}{l}104 \\
\text { RF }\end{array}$ & $\begin{array}{l}105 \\
\mathrm{Db}\end{array}$ & $\begin{array}{l}106 \\
\mathrm{Sg}\end{array}$ & $\begin{array}{l}107 \\
\text { Bh }\end{array}$ & $\begin{array}{l}108 \\
\text { IIs }\end{array}$ & $\begin{array}{l}109 \\
\text { Mit }\end{array}$ & $\begin{array}{l}110 \\
\text { Ds }\end{array}$ & $\begin{array}{l}111 \\
\mathbf{R g}\end{array}$ & $\begin{array}{l}112 \\
\mathrm{C}_{\mathbf{n}}\end{array}$ & $\begin{array}{l}113 \\
\text { Nh }\end{array}$ & $\begin{array}{c}114 \\
\text { FI }\end{array}$ & $\begin{array}{l}115 \\
\text { Mc }\end{array}$ & $\begin{array}{l}116 \\
\text { Lv }\end{array}$ & $\begin{array}{c}117 \\
\text { Ts }\end{array}$ & $\begin{array}{l}118 \\
\mathrm{Og}\end{array}$ & Eue & $\begin{array}{l}120 \\
\text { Ubn }\end{array}$ \\
\hline $\begin{array}{l}\text { Cones- } \\
\text { civs } \rightarrow\end{array}$ & 19 & 20 & $"$ & $n$ & 3 & 24 & 25 & 26 & 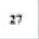 & $2 x$ & 3 & 90 & 3 & $s z$ & , & 10 & 11 & 12 & 13 & 14 & 15 & 16 & 17 & 18 & $s$ & 6 & , & s & ' & 2 & $s$ & 4 \\
\hline
\end{tabular}

Рис. 9. Нетрадиционная «левосторонняя» версия «супердлиннопериодического» варианта системы химических элементов, предложенная Жанетом [20] 
но не своей сущностью, хотя известны и такие их модификации, которые связаны с той или иной перестановкой отдельных химических элементов, например показанный на Рис. 6, где за пределами собственно таблицы помимо $4 f$ - и $5 f$-элементов оказались еще и $3 d-, 4 d$ - и $5 d$-элементы, входящие в «традиционном» версии «короткопериодического» варианта в VIII группу, или нетрадиционные версии «супердлиннопериодического», представленные на Рис. 7 и Рис. 8. Заметим в этой связи, что сам первооткрыватель Периодического Закона отрицательно относился к различного рода геометрическим построениям

Периодической системы, за исключением табличных; во всяком случае, в 1889 г., спустя 20 лет после открытия Периодического Закона, он говорил, что его «...следует выражать не геометрическими линиями, всегда подразумевающими сплошность, а вроде того, как поступают в теории чисел- прерьвно. По этим соображениям, я никогда не выражал и выражать не буду периодических отнотений никакими геометрическими фигурами». И действительно, жизнь показала, что ни одна из предложенных новых геометрических форм построения системы химических элементов, за исключением табличной, не нашла сколь-нибудь широкого применения. Исследовательская мысль и дизайнерская фантазия в этом направлении в основном поработали «вхолостую», ибо сколько-нибудь значительное распространение получили лишь табличные формы (и притом лишь две из них, а именно упомянутые выше «короткопериодический» и «длиннопериодический» варианты). Однако и большинство этих таблиц, оттеняя периодичность изменения тех или иных свойств элементов и их соединений, ничего принципиально нового не внесли в конструкцию Периодической системы. Изменение свойств элементов связано со строением электронной оболочки атома, точнее, с суммарной «емкостью» $p$-, $d$ - и $f$-электронных уровней, равной 8,18 и 32. Отсюда, естественно вытекает три основных варианта табличного изображения системы элементов, расположенных в порядке увеличения заряда ядра атома, а именно 8-клеточные («короткопериодический»), 18-клеточный («длиннопериодический») и 32-клеточные («супердлиннопериодический» вариант). Возможен, однако, как минимум и еще один вариант, а именно 16-клеточный, но о нем скажем позже, а пока отметим отдельные из наиболее часто встречающихся нетабличных вариантов системы химических элементов. Среди них в первую очередь следует выделить спиральные и концентрические, сведения о которых можно найти в $[18,21-30]$. Одной из простейших следует признать систему В.И. Се-

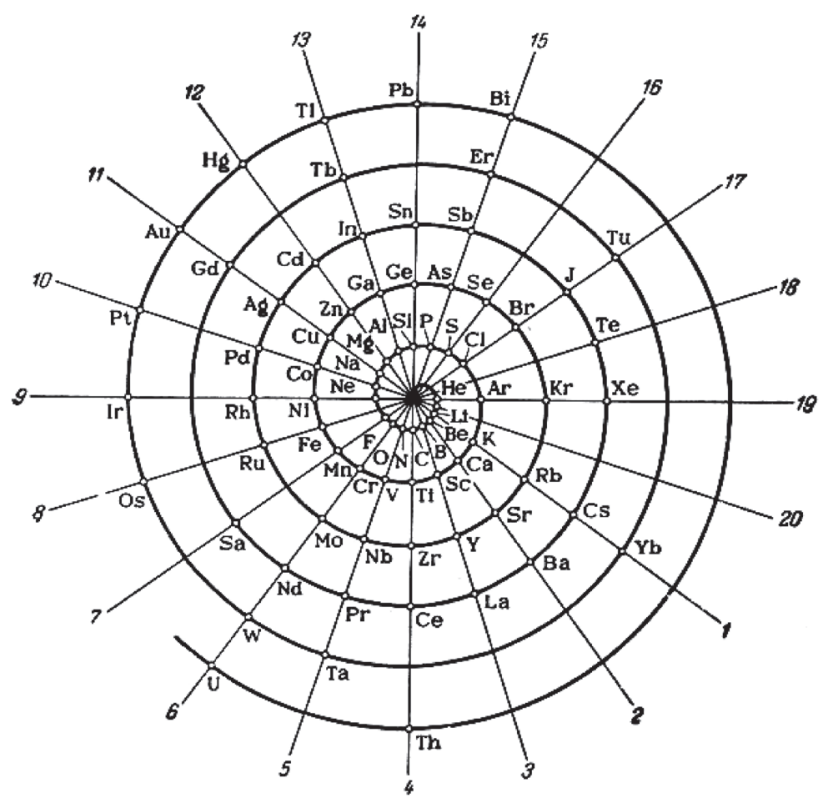

Рис. 10. Простой «спиральный» вариант системы химических элементов [21]

мишина [21] (Рис. 9), являющуюся по сути не чем иным, как модификацией «спирали Баумгауэра», предложенной им еще в 1870 г., т.е. почти сразу же после того, как был открыт Периодический Закон. Искусственность построения этой системы, однако, совершенно очевидна: число элементов на радиальных линиях колеблется от одного (линия 18) до шести (линия 6); 29 мест пересечения радиальных линий со спиралью не заняты элементами, некоторые элементы оторваны от своих аналогов (например, N, O, F, Ne), а элементы $\mathrm{Gd}, \mathrm{Tb}, \mathrm{Er}, \mathrm{Tm}, \mathrm{Yb}$ и другие ничего общего не имеют с элементами, находящимися на данных радиальных линиях; невозможно определить, где начало и конец периодов, а стало быть, и число элементов в них; нет доказательств расположения того или иного элемента между двумя другими [21]. В периодической системе Т. Бенфея [22], предложенной в 1960 г., элементы образуют двухмерную спираль, которая, раскручиваясь, опоясывает своеобразные «острова» с «переходными» $(3 d-$, $4 d-, \quad 5 d$-) лантаноидами $(4 f-)$ и актиноидами (5f-элементами) (Рис. 10). «Спиральный» вариант Я. Шолтена [23] можно рассматривать как некое дальнейшее развитие «спирального» варианта, представленного в [21], в котором уже все места пересечения радиальных линий со спиралью заняты теми или иными химическими элементами (Рис. 11). Известны и еще более сложные «спиральные» варианты [24-27], примеры которых представлены на Рис. 12-15; при этом в некоторых из таких вариантов (Рис. 15) имеет место своего 
рода сочетание «спирального» и «объемного» мотивов-«спирально-сферический» и «спиральнопсевдосферический» на базе геометрического тела с постоянной отрицательной кривизной (т.н. псевдосферы Бельтрами, являющейся одним из вариантов интерпретации геометрии Лобачевского) [27]. В связи с этим небезынтересно отметить, что идею относительно представления системы химических элементов в спиральной

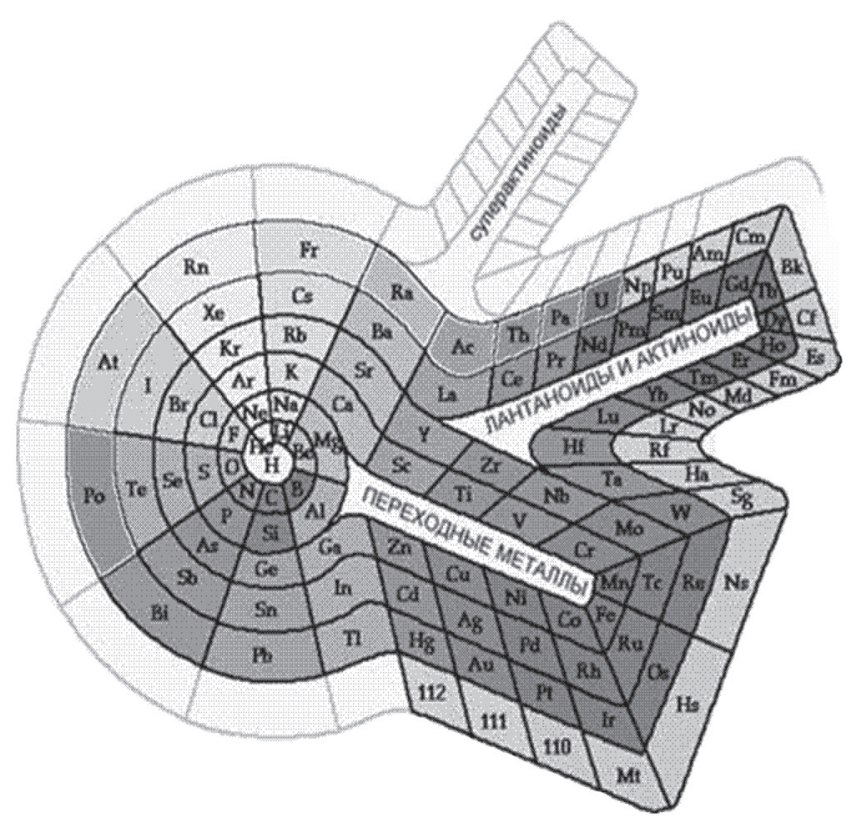

Рис. 11. «Спиральный» вариант системы химических элементов Бенфея [22]

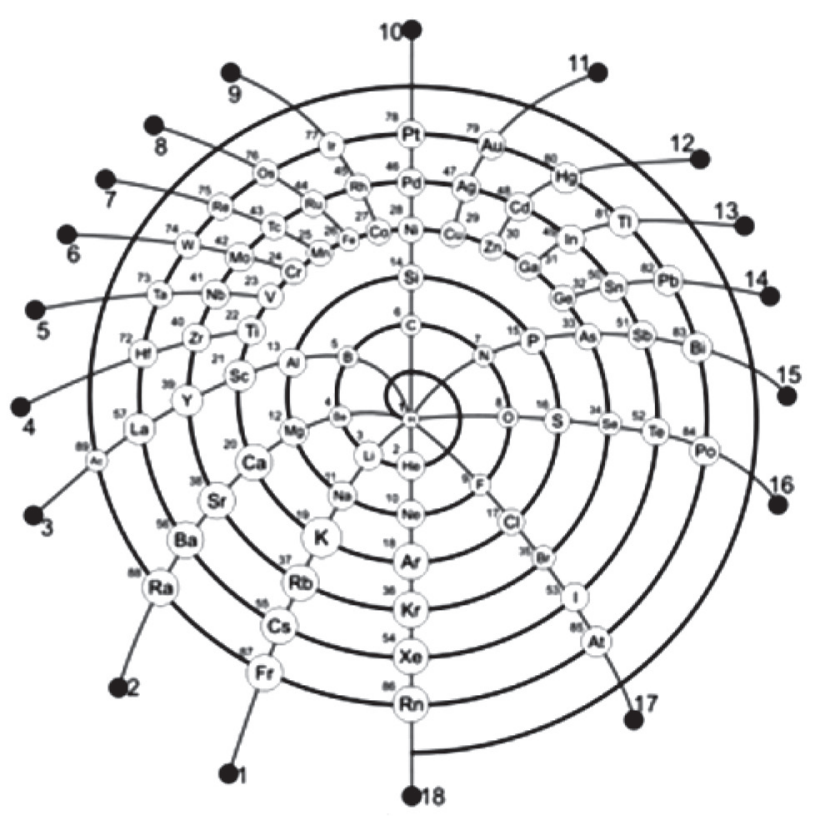

Рис. 12. «Спиральный» вариант системы химических элементов Шолтена [23] форме высказывал сам Д.И. Менделеев, причем уже в самой своей первой статье о Периодическом Законе [9]. Позднее же в статье «Периодическая законность химических элементов» он писал: «B сущности же все распределение элементов представляет непрерывность и отвечает до некоторой степени спиральной функции» (жирный курсив

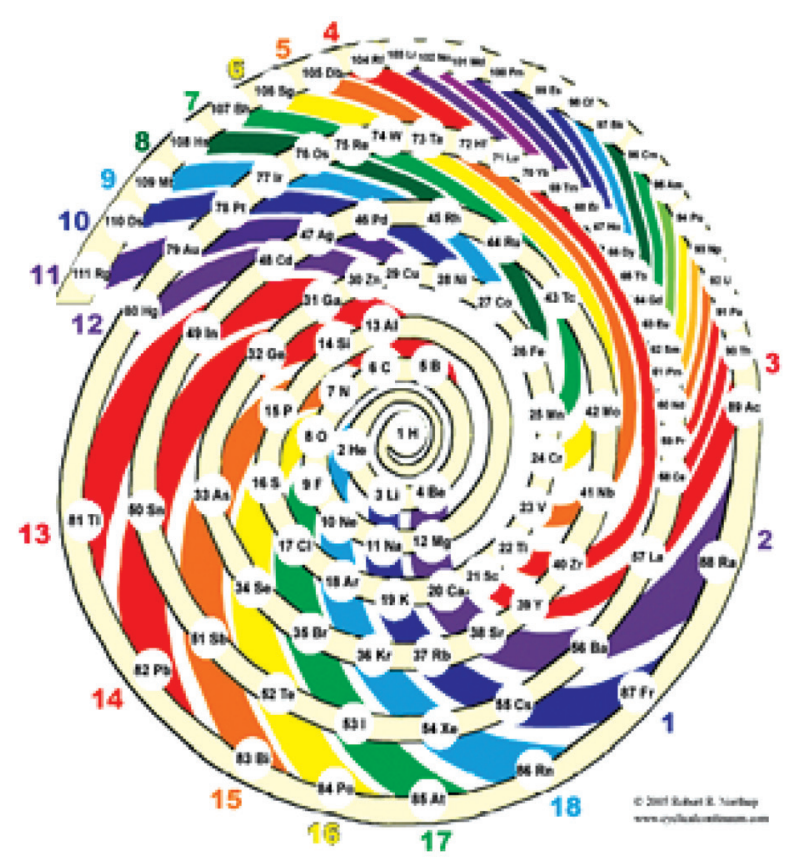

Рис. 13. «Спиральный» вариант системы химических элементов Нортхэпа [23, 24]

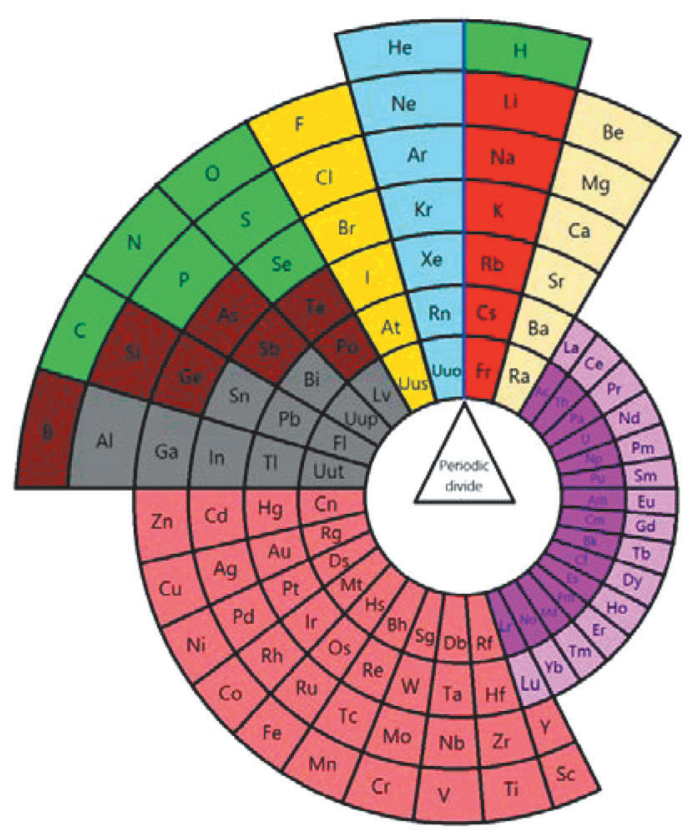

Рис. 14. «Спиральный» вариант системы химических элементов [25] 

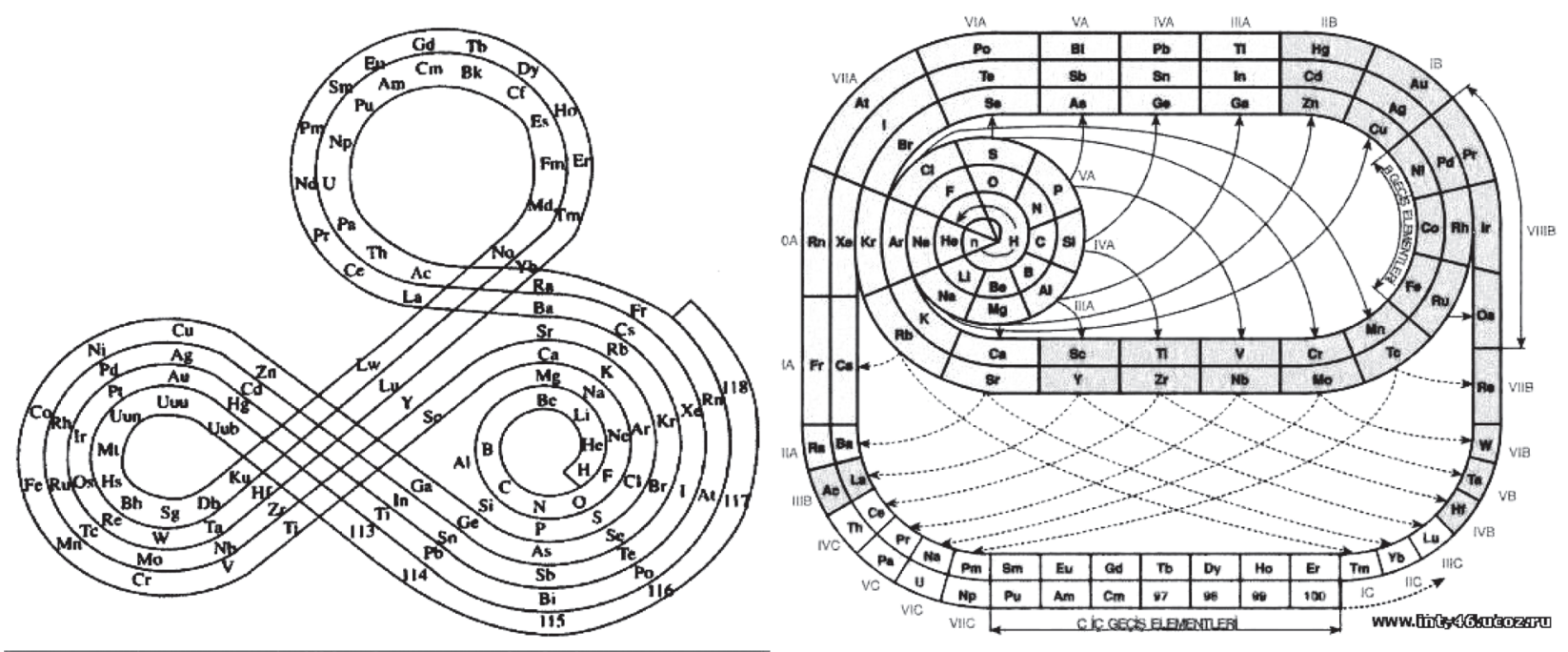

Рис. 15. «Спиральные» варианты системы химических элементов [26]
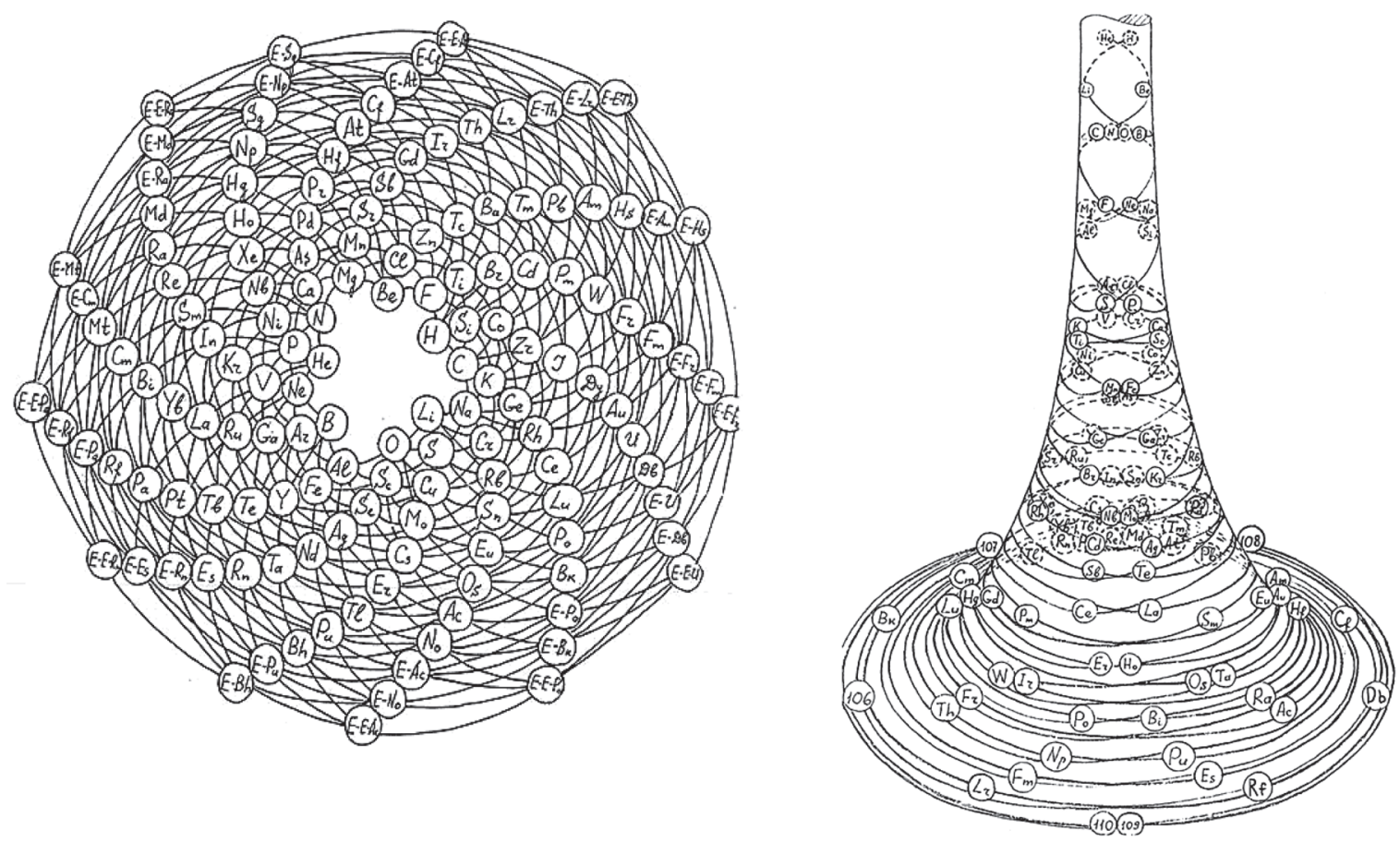

Рис. 16. «Спирально-сферический» и «спирально-псевдосферический» варианты системы химических элементов [27]

мой. - О.М.). И тем не менее, как уже указывалось нами несколько выше, «никогда не выражал... периодических отночений никакими геометрическими фигурами».

Близким к «спиральным» вариантам системы химических элементов можно считать т.н. концентрические системы, идея которых сводится к размещению символов элементов в пределах площадей, ограниченных параллельно расположенными кривыми или прямыми линиями. Наиболее распространенным здесь является концен- трические системы с использованием концентрических окружностей, примеры которых представлены в [26, 28-30] и на Рис. 16-18. По мнению одного из авторов таких систем, индийского исследователя М. Абубара, подобная система отражает также и относительный размер атомных ядер, поскольку размеры ячеек к краю таблицы увеличиваются $[17,28]$. В развитие модели с концентрическими окружностями были предложены и более сложные варианты, в которых эти окружности располагались уже на сферической поверхности, 
т.е. в рамках трехмерного пространства. Примеры таких моделей можно найти в источниках $[23,31]$. В [30] представлен концентрический вариант системы химических элементов, в которой использованы подобные друг другу правильные восьмиугольники (Рис. 19). Предлагались и другие варианты, в частности «мозаичные» [26,29], примеры которых даны на Рис. 20-21, «пирамидальные» [32] (Рис. 22) и др. [33-38].

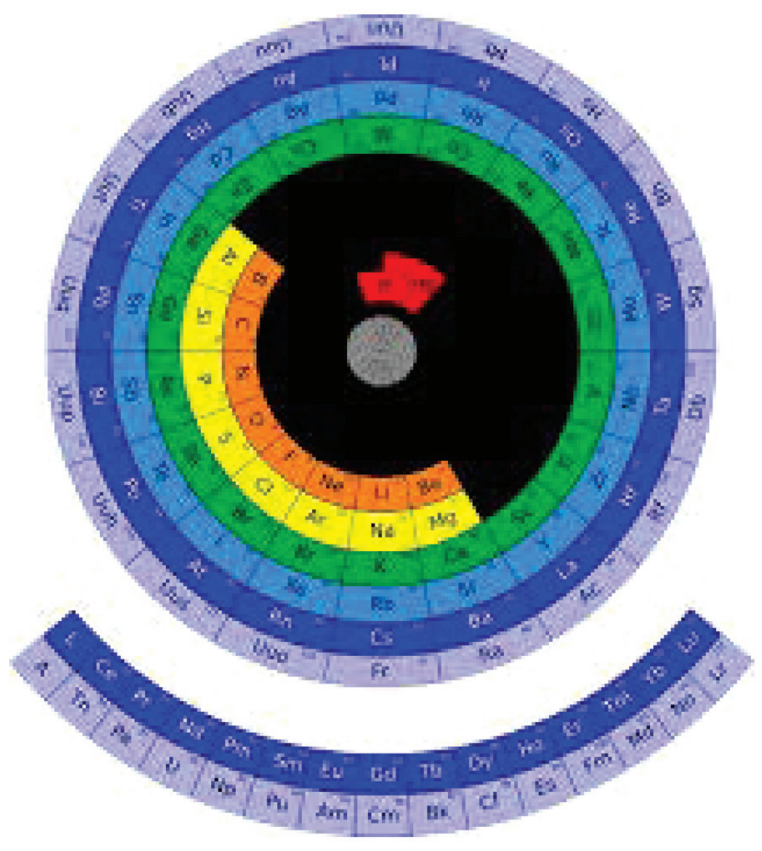

Рис. 17. «Концентрический» вариант системы химических элементов $[17,28]$

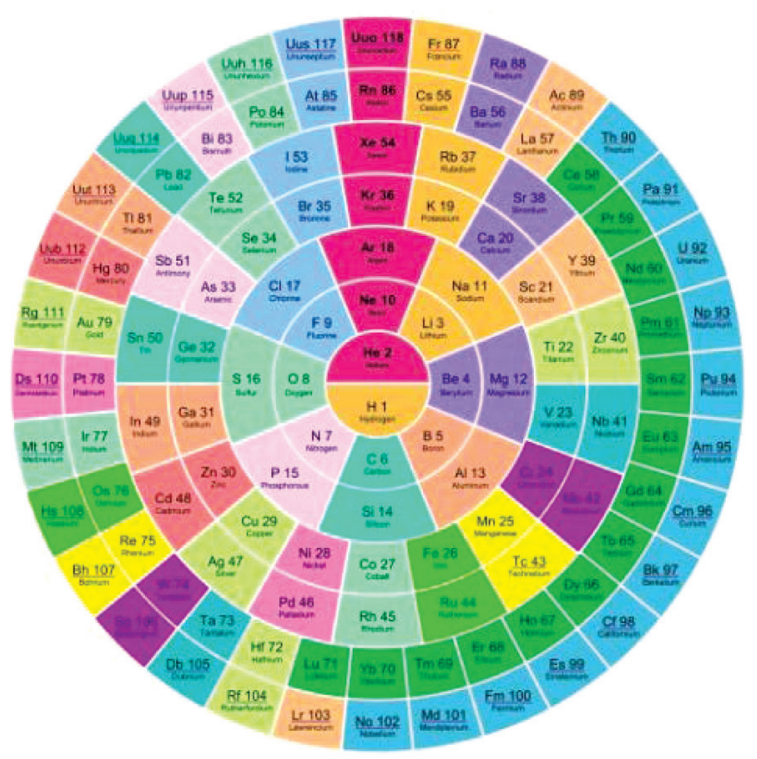

Рис. 18. «Концентрический» вариант системы химических элементов [29]
Мы упомянули здесь лишь о наиболее распространенных вариантах интерпретации Периодического Закона; сколько же их всего было предложено за 150-летнюю историю Периодического Закона, точно указать вряд ли возможно: по одним сведениям [17] их более 500, по другим [38, 39] таковых уже к 1975 г. было почти 700, по третьим [27] свыше 1000 (!). Наиболее надежной, на наш взгляд, является вторая из этих цифр - по крайней мере, она подтверждается совокупностью вариантов системы элементов, приведенной в монографии [38],

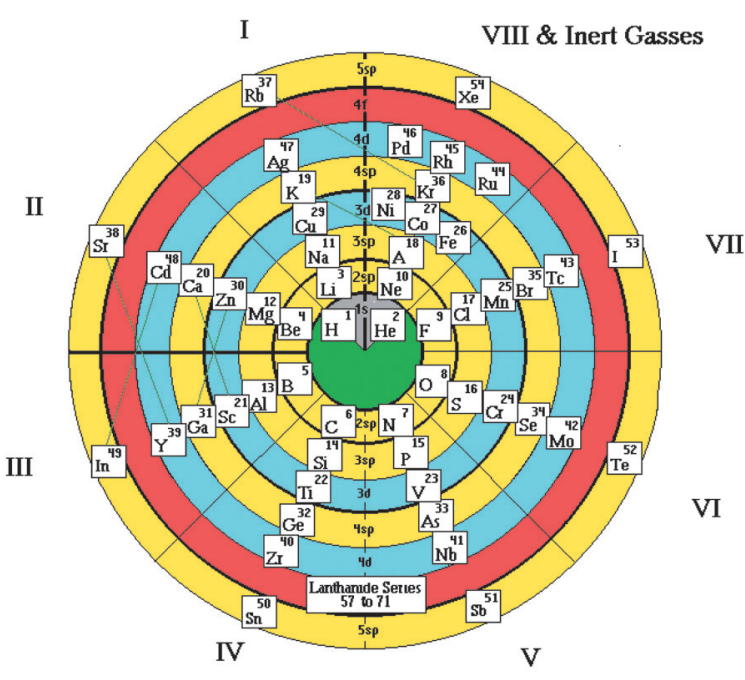

Рис. 19. «Концентрический» вариант системы химических элементов [26]

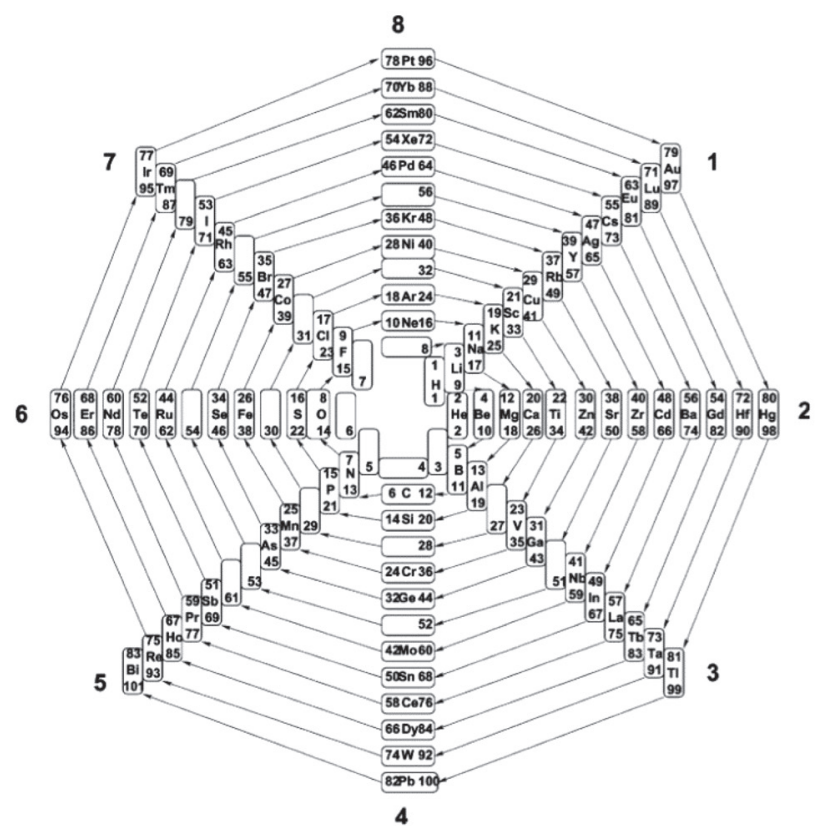

Рис. 20. «Концентрический» вариант системы химических элементов [30] 


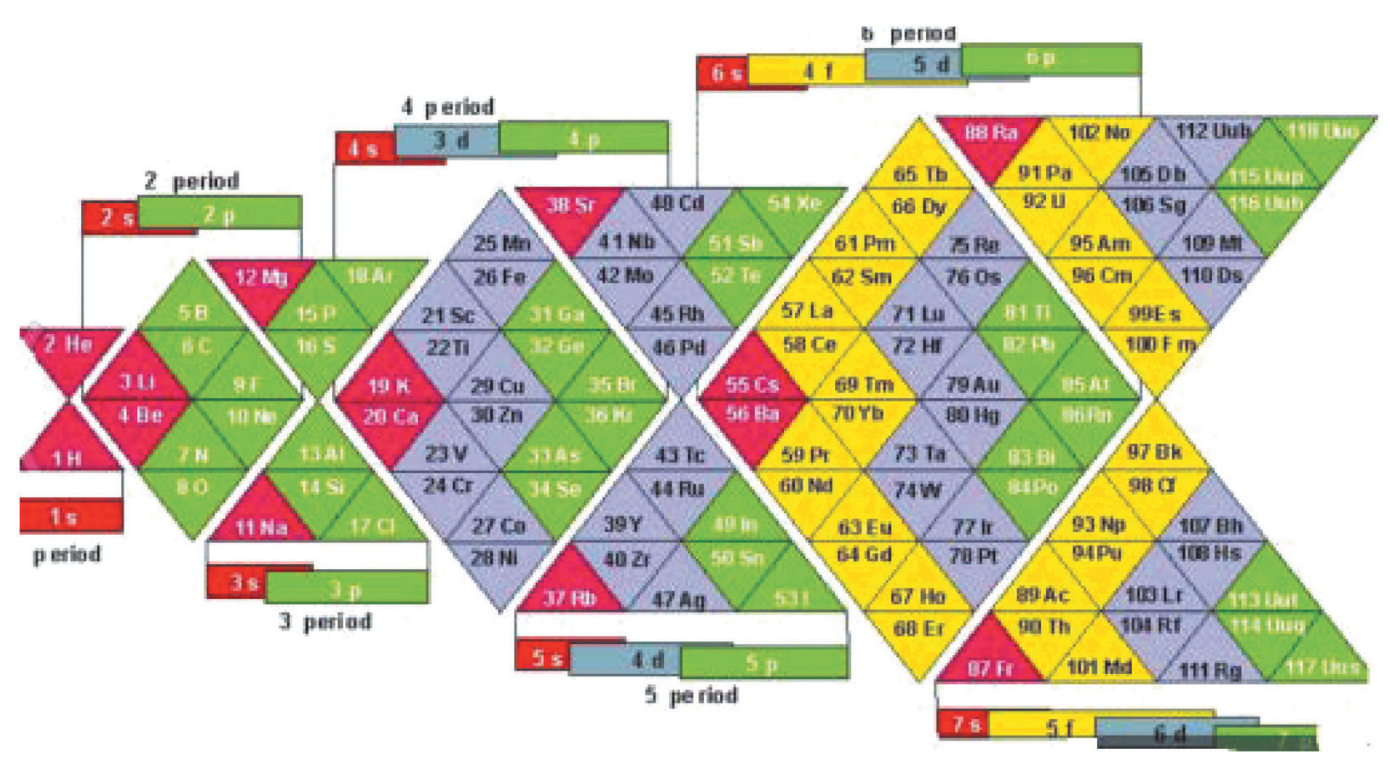

Рис. 21. «Мозаичный» вариант системы химических элементов [29]

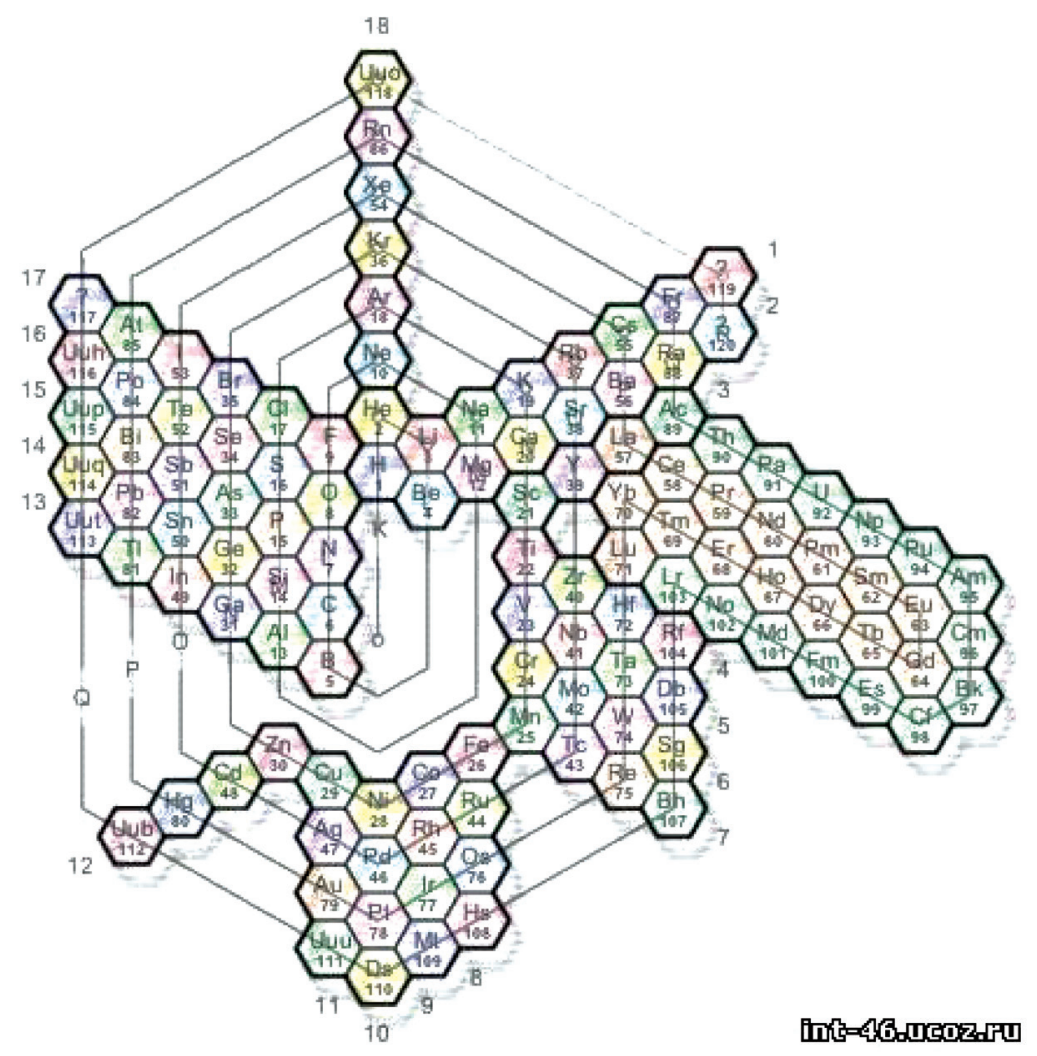

Рис. 22. «Мозаичный» вариант системы химических элементов [26]

где они собраны воедино. И подводя итоги вышеизложенному, подчеркнем следующее важное обстоятельство: подавляющее большинство предложенных этих вариантов оказалось невостребованными ни научным, ни педагогическим сообществами. Хотя многим из этих вариантов и нельзя отказать в оригинальности, они оказались интересными по сути дела лишь для дизайнеров от химической и физической наук. Читатель данной статьи, наверное, обратил внимание на то, что целый ряд вариантов систем химических элементов процитирован лишь по соответствующим страницам 
в Internet, без указания их авторов и литературных источников, где они опубликованы; дело в том, что этих самых авторов установить оказалось просто невозможным. Да и в эту «всемирную паутину» эти варианты системы химических элементов попали скорее всего благодаря разного рода энтузиастам от т.н. «народной науки». Отчасти это досадное обстоятельство связано с тем, что творческие усилия на этом поприще физико-химическим научным сообществом, да иными другими (по крайней мере, российскими и советскими), мягко говоря, не очень-то приветствовались и не находили своего отражения не то что в сугубо научных журналах, но даже и в популярных. (Достаточно сказать в связи с этим, что едва ли не в момент основания такого известного журнала, как «Химия и жизнь», его редколлегия приняла специальное решение - никогда (!) не публиковать на его страницах какие бы то ни было варианты Периодической системы химических элементов). И словно в подтверждение расхожего в нашем народе афоризма «развитие идет по спирали», эволюция всех этих вариантов началась с «табличного» варианта и, можно сказать с полным на то правом, табличными же и завершилась, ибо ныне в ходу у хими- ков (да и не только у них) лишь два варианта - «короткопериодический» и «длиннопериодический». И полагать, что в обозримом будущем эти варианты будут вытеснены каким-либо другим альтернативным, причем НЕтабличным вариантом, нет решительно никаких оснований, хотя вполне возможно и даже весьма вероятно, что число этих самых «альтернатив» продолжит пополняться. (Заметим в связи с этим, что сам Менделеев уже после того, когда его детище вошло в научный обиход, высказал довольно-таки интересную идею (пусть и в весьма абстрактной форме), которая пока что осталась нереализованной ни в одной из многочисленных предложенных после него вариантов графической интерпретации Периодического Закона: «..система требует телесной формы, допускающей сближение по всем направлениям» [27]).

Оба эти два варианта, несмотря на свою популярность (во втором случае - даже планетарную), не лишены недостатков. «Короткопериодический» вариант, в котором 8 групп, имеет, однако, как минимум три таковых; во-первых, $d$-элементы в рамках каждого из тех периодов, где они присутствуют (а именно - начиная с четвертого), располагаются как бы в «два этажа» (Табл. 1); во-вторых,

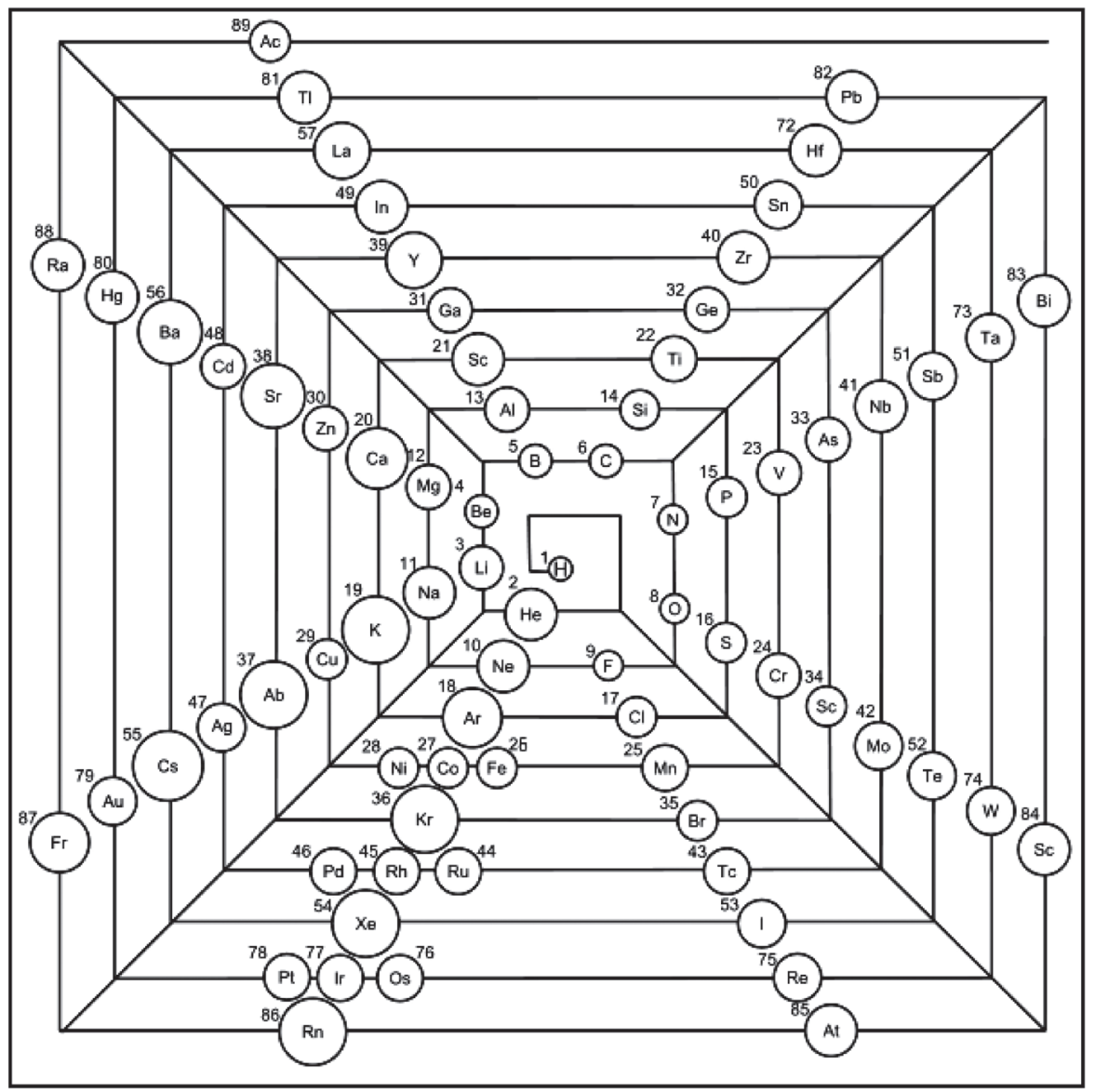

Рис. 23. «Пирамидальный» вариант системы химических элементов [32] 
$f$-элементы (лантаноиды и актиноиды) здесь находятся по существу уже не в самой таблице, а вынесены за ее пределы в виде неких «приложений»; в-третьих, при любом из двух возможных (и принятых) вариантов расположения первого из всех химических элементов - водорода (в первой или в седьмой группах) в этой самой таблице остается шесть (!) ПУСТЫХ КЛЕТОК, и чем их заполнить, непонятно. «Длиннопериодический вариант» А. Вернера, в котором 18 групп, позволяет устранить первый из указанных выше недостатков, однако второй и третий в нем сохраняются (Рис. 5). Справедливости ради следует сказать, что логическое развитие этого варианта дает возможность устранить и второй недостаток, поместив аналогичным образом в таблицу и $f$-элементы, но тогда число групп возрастет до 32 и таблица существенно увеличится по своей ширине. А если еще учесть, что нынешнее число известных химических элементов (118) - это отнюдь не конец их «мира», и на подходе еще одна, пока что неизвестная химикам их категория $-5 g$-элементы, первый из которых согласно современной теории строения атома должен иметь заряд ядра $Z=121$, последний же - 138, и если мы будем стремиться разместить и их в одной таблице с $s$-, $p$-, $d$ - и $f$-элементами, то после их открытия число групп в ней возрастет до 50 (!). Вряд ли это будет удобно для пользователей. Но как бы то ни было, последний, третий из указанных выше недостатков «табличного» варианта оказывается не устраненным даже в таком «супердлиннопериодическом» формате. В связи с этим, наверное, стоит задуматься о том, нельзя ли как-то модифицировать именно «короткопериодический» ТАБЛИЧНЫЙ ВАРИАНТ Периодической системы, дабы преодолеть именно ЭТОТ недостаток. А заодно, если получится, - то и два остальных.

\section{«Полудлиннопериодический» вариант}

В «короткопериодическом» варианте положение конкретного элемента определяется двумя параметрами - зарядом его нуклида $Z$, совпадающим с порядковым номером элемента, и его наивысшей возможной степенью окисления. Подобный принцип «заселения» элементов в целом хорошо оправдывает себя, однако степень окисления (в том числе и максимальная) - это лишь одно из свойств химического элемента, которое, равно как и все другие, есть лишь следствие проявления одной и той же ПРИЧИНЫ, связанной с электронной структурой атомов химического элемента. Получается, что в качестве одного из параметров, определяющих положение конкретного элемента в пери- одической системе, мы выбираем во всех случаях то свойство, которое является своеобразным «производным» от этой самой причины, что, очевидно, уже само по себе не вполне логично.

Как уже упоминалось выше, Д.И. Менделеев вскрыл факт закономерного изменения свойств химических элементов с ростом атомных масс и сформулировал Периодический Закон, но не причину того феномена, что лежит в его основе. В его время теории строения атома еще не существовало, и он при построении своей системы, не располагая данными о причине явления, вынужден был ориентироваться на то его следствие (в данном случае - некоторое свойство элемента), в свете которого сама «периодичность химических элементов» выглядела бы наиболее рельефно. Этим свойством оказалась максимальная валентность, хотя и при ее использовании в качестве второго параметра (наряду с атомной массой) при построении системы элементов без определенных издержек не обошлось. У нас же есть одно, весьма существенное преимущество перед Д.И. Менделеевым: мы знаем причину периодичности и отклонений от нее - и то, и другое прямо связаны со спецификой заполнения электронами атомных орбиталей (AO) и соответственно - электронным строением атомов. Именно его и следует взять в качестве второго параметра при построении системы химических элементов, на что и было в свое время прямо указано автором этих строк в статье [40].

Начать модификацию «короткопериодического» варианта, на наш взгляд, следует с устранения того самого недостатка, который присущ ЛЮБОМУ из основных современных табличных вариантов Периодической системы, а именно - ликвидации тех самых шести пустых клеток, о которых уже упоминалось выше. Для этого взглянем на сложившуюся ситуацию под иным утлом зрения и поместим в самом начале, в ее верхнем левом углу водород Н, а за ним без каких бы то ни было промежутков следующие за ним элементы в порядке возрастания заряда ядра $\mathrm{Z}: \mathrm{He}, \mathrm{Li}, \mathrm{Be}, \mathrm{B}, \mathrm{C}$, $\mathrm{N}$ и т.д. Внимательно присмотревшись к их свойствам, мы до кислорода включительно не обнаружим похожих друг на друга элементов ни по химическим свойствам, ни - что еще более важно по строению внешних электронных оболочек. А вот девятый по счету химический элемент - F пусть далеко не во всем, но как раз в главком строении электронной оболочки, которую мы взяли в качестве второго параметра при построении таблицы элементов - уже мОЖЕТ РАССМАТРИВАТЬСЯ как АНАЛОГ Н, ибо обоим этим элементам до заполнения внешней электронной не хватает по одному электрону, пусть даже их электронные 
конфигурации и существенно различаются $\left(1 s^{l}-\right.$ у водорода и $2 s^{2} 2 p^{5}-$ у фтора). Следующий за ним элемент - Ne по своему электронному строению аналогичен Не и подобно ему имеет полностью заполненные АО (хотя и здесь имеет еще место различие в электронных конфигурациях: $\mathrm{He}-1 s^{2}, \mathrm{Ne}-$ $2 s^{2} 2 p^{\circ}$ ). В дальнейшем аналогия в строении электронных оболочек становится полной: $\mathrm{Li}$ и $\mathrm{Na}-2 \mathrm{~s}^{l}$ и $3 \mathrm{~s}^{l}$ соответственно, $\mathrm{Be}$ и $\mathrm{Mg}-2 \mathrm{~s}^{2}$ и $3 \mathrm{~s}^{2}$, $\mathrm{B}$ и $\mathrm{Al}-$ $2 \mathrm{~s}^{2} 2 p^{l}$ и $3 \mathrm{~s}^{2} 3 p^{l}$ и т.д. до $\mathrm{S}$, оказывающейся аналогом О ( $2 \mathrm{~s}^{2} 2 p^{4}$ и $3 \mathrm{~s}^{2} 3 p^{4}$ соответственно). Обратим теперь внимание на такое обстоятельство: $\mathbf{y}$ третьего по счету элемента в периодической системе - Li на внешнем слое находится один электрон, у четвертого - Ве - два, у пятого - В - три и т.д. до О, у которого шесть электронов. И вполне естественно поместить их в группы, придав им номера, соответствующИе чИСЛУ элЕКТРОНОВ НА ВНЕШНЕМ СлоЕ: тогда Li окажется в группе $\underline{\mathrm{I}}, \mathrm{Be}$ в группе $\underline{\mathrm{II}}$, $\mathrm{O}$ - в группе $\underline{\mathrm{VI}}$. А вот Не имеет устойчивую двухэлектронную оболочку $1 s^{2}$, НА ВНЕшНЕМ СЛОЕ у него НЕТ НИ одНого электрона. В соответствии с указанной выше логикой нумерации групп химических элементов его следует поместить в нулевую группу, но никак не в группу VIII, как это сделано в современном «короткопериодическом» (и уж тем более - не в группу XVIII, как в «длиннопериодическом») варианте. Кстати, сам Д.И. Менделеев в первоначальном СВОЕМ варианте Периодической системы (Рис. 3) выделил Не и все остальные аналогичные ему элементы (т.н. инертные газы) именно в нулевую группу и был категорически против их размещения в группе восьмой. У самого же первого элемента системы - водорода до заполнения внешней электронной оболочки не хватает одного электрона, и теперь в полном соответствии с вышеуказанной логикой его следует поместить в минус первую группу. Решение это кажется парадоксальным, однако оно позволяет полностью ликвидировать все пустые клетки в первом периоде. Продолжая же «заселение» химических элементов в рамках подобной логики, мы легко сможем разместить в ней все известные ныне химические элементы в рамках принципа «номер группы = число электронов на внешней оболочке». Некоторые сложности, правда, возникают с Со и $\mathrm{Ni}$, а также их аналогами, имеющими аналогичную электронную конфигурацию $(n-1) d^{7} n s^{2}$ и $(n-1) d^{8} n s^{2}$ соответственно - Rh и Pd по той простой причине, что число электронов на валентных уровнях у них равно 9 и 10 соответственно. В современном варианте периодической системы, равно как и в первоначальной ее интерпретации самого Д.И. Менделеева, они помещены вместе с Fе и его аналогом $\mathrm{Ru}$ в одной обширной восьмой группе, что уже само по себе выглядит неестественным [41]. Кроме того, парам Co-Rh и Ni-Pd вообще нет аналогов среди всех элементов от первого до 57-го включительно, а раз так, то их следует поместить в две самостоятельные группы, а именно в $\underline{\mathrm{X}}$ и $\underline{\mathrm{X}}$ соответственно. Тот же самый принцип «заселения» может и должен быть использован и для $f$-элементов. Первый из них $-\mathrm{Ce}$ c Z $=58$ имеет электронную конфигурацию внешних АО $4 f^{2} 6 s^{2}$ и четыре валентных электрона, так что ему место в группе IV, а не в III, где он ныне значится. Аналогично расположатся в таблице и другие $4 f$-элементы: $\operatorname{Pr}$ с конфигурацией $4 f^{3} 6 s^{2}-$ в $\underline{\mathrm{V}}, \operatorname{Sm}\left(4 f^{6} 6 s^{2}\right)-$ в VIII, Tb $\left(4 f^{9} 6 s^{2}\right)$ - в $\underline{\mathrm{XI}}$ и т.д. вплоть до $\operatorname{Er}\left(4 f^{12} 6 s^{2}\right)$, который займет клетку в группе XIV. А вот следующий же за ним элемент - Tm $\left(4 f^{14} 6 s^{T}\right)$ с полностью заполненным электронами $4 f-\mathrm{AO}$ и одним электроном на $6 s-\mathrm{AO}$, в рамках все той же логики должен быть помещен в группу I. И, наконец, два последних $4 f$-элемента - Yb и Lu займут соответствующие клетки в группах II и III группах. Разместить остальные известные ныне химические элементы после всего сказанного уже не составит большого труда, и в итоге система химических элементов приобретает вид, представленный на Рис. 23. В этом новом формате $f$-элементы располагаются наравне с остальными элементами в соответствующих группах; более того, даже сами понятия «лантаноиды» и «актиноиды» теряют свой изначальный смысл. Да и внешне он выглядит изящнее по сравнению как с «короткопериодическим», так и с «длиннопериодическим» (и тем более - «супердлиннопериодическим») вариантами. В нем, как нетрудно заметить, 16 групп, что даже меньше, чем в «длиннопериодическом» варианте. Когда же физикам и химикам станут известны $5 g$-элементы (а это, хотелось бы надеяться, случится уже в ближайшие годы), число групп станет равным 20, что намного меньше числа групп в «супердлиннопериодическом» варианте (50).

Даже беглого взгляда на новый вариант таблицы химических элементов (который можно условно назвать «полудлиннопериодическим») достаточно, чтобы отметить: исчезли все неопределенности, связанные с положением водорода (равно как и пустые клетки между ним и гелием), более четким и определенным стало положение галогенов, инертных газов, лантаноидов и актиноидов. Вместо семи периодов как в «короткопериодическом», так и в «длиннопериодическом» вариантах «полудлиннопериодический» вариант при известной ныне совокупности химических элементов (118) содержит лишь ЧЕТЫРЕ периода (причем последний, четвертый, только начат и включает в себя лишь два элемента - Ts и Og), при этом 


\begin{tabular}{|c|c|c|c|c|c|c|c|c|c|c|c|c|c|c|c|c|}
\hline \multicolumn{17}{|c|}{ ГРУППЫ ХИМИЧЕСКИХ ЭЛЕМЕНТОВ } \\
\hline & - I & $\mathbf{0}$ & I & II & III & IV & $\mathbf{V}$ & VI & VII & VIII & IX & $\mathbf{X}$ & XI & XII & XIII & XIV \\
\hline \multirow[b]{2}{*}{1} & ${ }^{1} \mathbf{H}$ & ${ }^{2} \mathrm{He}$ & ${ }^{3} \mathrm{Li}$ & ${ }^{4} \mathrm{Be}$ & ${ }^{5} \mathrm{~B}$ & ${ }^{6} \mathrm{C}$ & ${ }^{7} \mathbf{N}$ & ${ }^{8} \mathrm{O}$ & & & & & & & & \\
\hline & ${ }^{9} \mathbf{F}$ & ${ }^{10} \mathrm{Ne}$ & ${ }^{11} \mathrm{Na}$ & ${ }^{12} \mathrm{Mg}$ & ${ }^{13} \mathrm{Al}$ & ${ }^{14} \mathrm{Si}$ & ${ }^{15} \mathbf{P}$ & ${ }^{16} \mathrm{~S}$ & & & & & & & & \\
\hline \multirow{4}{*}{2} & ${ }^{17} \mathrm{Cl}$ & ${ }^{18} \mathrm{Ar}$ & ${ }^{19} \mathbf{K}$ & ${ }^{20} \mathrm{Ca}$ & ${ }^{21} \mathrm{Sc}$ & ${ }^{22} \mathrm{Ti}$ & ${ }^{23} \mathrm{~V}$ & ${ }^{24} \mathrm{Cr}$ & ${ }^{25} \mathbf{M n}$ & ${ }^{26} \mathrm{Fe}$ & ${ }^{27} \mathrm{Co}$ & ${ }^{28} \mathrm{Ni}$ & & & & \\
\hline & & & ${ }^{29} \mathrm{Cu}$ & ${ }^{30} \mathbf{Z n}$ & ${ }^{31} \mathbf{G a}$ & ${ }^{32} \mathrm{Ge}$ & ${ }^{33} \mathrm{As}$ & ${ }^{34} \mathrm{Se}$ & & & & & & & & \\
\hline & ${ }^{35} \mathrm{Br}$ & ${ }^{36} \mathbf{K r}$ & ${ }^{37} \mathbf{R b}$ & ${ }^{38} \mathrm{Sr}$ & ${ }^{39} \mathbf{Y}$ & ${ }^{40} \mathbf{Z r}$ & ${ }^{41} \mathbf{N b}$ & ${ }^{42} \mathrm{Mo}$ & ${ }^{43} \mathrm{Tc}$ & ${ }^{44} \mathrm{Ru}$ & ${ }^{45} \mathrm{Rh}$ & ${ }^{16} \mathrm{Pd}$ & & & & \\
\hline & & & ${ }^{47} \mathbf{A g}$ & ${ }^{48} \mathrm{Gd}$ & ${ }^{49} \mathbf{I n}$ & ${ }^{50} \mathrm{Sn}$ & ${ }^{51} \mathrm{Sb}$ & ${ }^{52} \mathrm{Te}$ & & & & & & & & \\
\hline \multirow{6}{*}{3} & ${ }^{53} \mathbf{J}$ & ${ }^{54} \mathrm{Xe}$ & ${ }^{55} \mathrm{Cs}$ & ${ }^{56} \mathrm{Ba}$ & ${ }^{57} \mathrm{La}$ & ${ }^{58} \mathrm{Ce}$ & ${ }^{59} \mathrm{Pr}$ & ${ }^{60} \mathrm{Nd}$ & ${ }^{61} \mathrm{Pm}$ & ${ }^{62} \mathrm{Sm}$ & ${ }^{63} \mathbf{E u}$ & ${ }^{64} \mathrm{Gd}$ & ${ }^{65} \mathrm{~Tb}$ & ${ }^{66} \mathrm{Dy}$ & ${ }^{67} \mathrm{Ho}$ & ${ }^{68} \mathrm{Er}$ \\
\hline & & & ${ }^{69} \mathrm{Tm}$ & ${ }^{70} \mathbf{Y b}$ & ${ }^{71} \mathbf{L u}$ & ${ }^{72} \mathbf{H f}$ & ${ }^{73} \mathbf{T a}$ & ${ }^{74} \mathbf{W}$ & ${ }^{75} \mathbf{R e}$ & ${ }^{76} \mathrm{Os}$ & ${ }^{77} \mathbf{I r}$ & ${ }^{78} \mathrm{Pt}$ & & & & \\
\hline & & & ${ }^{79} \mathrm{Au}$ & ${ }^{80} \mathrm{Hg}$ & ${ }^{81} \mathrm{Tl}$ & ${ }^{82} \mathrm{~Pb}$ & ${ }^{83} \mathrm{Bi}$ & ${ }^{84} \mathrm{Po}$ & & & & & & & & \\
\hline & ${ }^{85}$ At & ${ }^{86} \mathbf{R n}$ & ${ }^{87} \mathrm{Fr}$ & ${ }^{88} \mathbf{R a}$ & ${ }^{89} \mathrm{Ac}$ & ${ }^{90} \mathrm{Th}$ & ${ }^{91} \mathbf{P a}$ & ${ }^{92} \mathrm{U}$ & ${ }^{93} \mathrm{~Np}$ & ${ }^{94} \mathrm{Pu}$ & ${ }^{95} \mathrm{Am}$ & ${ }^{96} \mathrm{Cm}$ & ${ }^{97} \mathrm{Bk}$ & ${ }^{98} \mathrm{Cf}$ & ${ }^{99} \mathrm{Es}$ & ${ }^{100} \mathrm{Fm}$ \\
\hline & & & ${ }^{101} \mathrm{Md}$ & ${ }^{102} \mathrm{No}$ & ${ }^{103} \mathrm{Lr}$ & ${ }^{104} \mathbf{R f}$ & ${ }^{105} \mathrm{Db}$ & ${ }^{106} \mathrm{Sg}$ & ${ }^{107} \mathrm{Bh}$ & ${ }^{108} \mathrm{Hs}$ & ${ }^{109} \mathrm{Mt}$ & ${ }^{110} \mathrm{Ds}$ & & & & \\
\hline & & & ${ }^{111} \mathbf{R g}$ & ${ }^{112} \mathrm{Cn}$ & ${ }^{113} \mathrm{Nh}$ & ${ }^{114} \mathbf{F I}$ & ${ }^{115} \mathrm{Mc}$ & ${ }^{116} \mathrm{Lv}$ & & & & & & & & \\
\hline
\end{tabular}

Рис. 24. «Полудлиннопериодический» 16-клеточный вариант системы химических элементов (для краткости химические элементы ${ }^{117} \mathrm{Ts}_{\mathrm{s}}{ }^{118} \mathrm{Og}$, начинающие собой новый период, здесь не показаны)

в каждом новом периоде впервые появляется и новая разновидность химических элементов (во втором - $d$-элементы, в третьем $-f$-элементы и в четвертом - $g$-элементы). Общее же количество элементов в каждом периоде определяется простым соотношением $N=4(n+1)^{2}$, где $n-$ номер периода. В этом новом варианте намечаются и новые закономерности, которые остались либо невскрытыми, либо необъяснимыми в рамках любого из двух вышеуказанных «табличных» вариантов периодической системы. Отметим лишь некоторые из них.

Вплоть до 60-х годов XX в. наиболее употребительным был «короткопериодический» вариант Периодической системы, в которой элементы Th, $\mathrm{Pa}$ и U помещались соответственно в IV, V и VI группах, после чего шли так называемые «трансурановые элементы», которые подобно $4 f$-элементам также выносились из основной таблицы в виде отдельного «приложения». А в учебниках химии того времени (см., например, [42]) Тh рассматривался как аналог $\mathrm{Ti}, \mathrm{Zr}$ и Hf, $\mathrm{Pa}$ - как аналог $\mathrm{V}, \mathrm{Nb}$ и Тa, U -как аналог Cr, Мо и W. После появления т.н. актиноидной концепции Сиборга Th, Pa и U перевели в когорту актиноидов, а позиции, которые они занимали, до поры до времени оставались вакантными. В настоящее время они заняты элементами с номерами 104 (Rf), 105 (Db) и 106 (Sg). B рамках актиноидной концепции, однако, оставалось (да и сейчас еще остается) не очень понятным, почему первые элементы этого ряда - от Ра до $\mathrm{Cm}$ - проявляют степени окисления, значитель- но превышающие +3 , хотя формально актиноиды, равно как и лантаноиды, «географически» примыкают к III группе что в «короткопериодическом», что в «длиннопериодическом» варианте. Предлагаемый же нами вариант периодической системы дает на это ответ: Th, Ра и U оказываются в ней именно в группах IV, V и VI соответственно, так что максимальные степени окисления этих элементов $(+4,+5$ и +6$)$ выглядят естественными и ожидаемыми. Более того, Np располагается здесь в седьмой группе, $\mathrm{Pu}$ - в восьмой, а стало быть, у обоих элементов могут существовать соединения со степенью окисления +7 , а у $\mathrm{Pu}-$ даже +8 . Еще более интересно то, что помещенные в первую группу $\mathrm{Tm}$ и $\mathrm{Md}$ в ряде случаев проявляют степень окисления +1 , причем у $\mathrm{Md}$ в кислых растворах она даже становится основной и из этих растворов данный элемент может быть осажден вместе с труднорастворимыми соединениями $s$-элементов I группы. Насколько известно автору этих строк, такой степени окисления у каких-либо других $f$-элементов до сих пор не отмечено. Другая пара $f$-элементов, a именно $\mathrm{Yb}$ и его аналог - No во многих соединениях проявляют степень окисления +2 , напоминая в этом отношении своих соседей по второй группе - $\mathrm{Sr}, \mathrm{Ba}$ и $\mathrm{Ra}$, что никак не вытекает ни из логики «короткопериодического», ни из логики «длиннопериодического» варианта, зато находит свое логичное объяснение в «полудлиннопериодическим» варианте, ибо в нем-то все они находятся в одной группе (а не в разных, как в вышеуказанных двух 
наиболее популярных ныне вариантах Периодической системы). К слову, металлический иттербий, подобно металлическим стронцию и барию, растворяется в жидком $\mathrm{NH}_{3}, \mathrm{a} \mathrm{YbSO}_{4}$ и $\mathrm{NoSO}_{4}$ столь же плохо растворимы в воде, как и $\mathrm{SrSO}_{4}, \mathrm{BaSO}_{4}$ и $\mathrm{RaSO}_{4}$. Добавим к сказанному, что первая триада $f$-элементов VIII-X групп (Sm, Eu, Gd) подобно первой триаде $d$-элементов из этих же групп (Fe, $\mathrm{Co}, \mathrm{Ni})$ обладает довольно-таки хорошо выраженным ферромагнетизмом.

В неорганической химии давно известен один любопытный факт, который может быть назван «эффектом пар» [42-44]. Смысл его сводится к тому, что по степени близости своих физико-химических характеристик элементы каждой из групп при движении по ней сверху вниз как бы сгруппированы попарно, причем различия между элементами в пределах одной пары заметно меньше, чем между элементами, находящимися в разных близлежащих парах. Например, во второй группе «попарное деление» дает пары $\mathrm{Be}-\mathrm{Mg}$, $\mathrm{Ca}-\mathrm{Sr}$ и $\mathrm{Ba}-\mathrm{Ra}$; как известно, различие между $\mathrm{Mg}$ и $\mathrm{Ca}$ заметно больше, чем между $\mathrm{Mg}$ и $\mathrm{Be}$, между $\mathrm{Sr}$ и $\mathrm{Ba}-$ больше, чем между $\mathrm{Ba}$ и $\mathrm{Ra}$ н т.д. Это обстоятельство в рамках любого из современных табличных вариантов Периодической системы как «короткопериодического», так и «длиннопериодического» - не удается объяснить с достаточной наглядностью. В «полудлиннопериодическом» же варианте (см. Табл. 23) оно представляется вполне естественным: ведь Ве и $\mathrm{Mg}$ относятся к ПЕРВОМУ периоду, Са и $\mathrm{Sr}$ - ко ВТОРОМУ, Ва и $\mathrm{Ra}-$ к ТРЕТЬЕМУ.

Предвижу следующее возражение против такого табличного варианта Периодической системы: в нем будет немало несоответствий между номером группы и проявляемой химическим элементом максимальной степени окисления. Едва ли, например, Rh и Pd будут способны проявлять в своих сколько-нибудь устойчивых химических соединениях степени окисления +9 и +10 , или $\mathrm{Bk}-+11$. В связи с этим заметим, что степень окисления это всего лишь одна из «граф» в «анкете» химического элемента и уже по этой причине она не может служить мерилом ценности той или иной их системы. Кстати, и оба «ключевых» современных варианта Периодической системы - «короткопериодический» и «длиннопериодический» по части соответствия между номером группы, где находится элемент, и максимальной степенью его окисления также довольно далеки от совершенства...

Как бы то ни было, одним из решающих критериев, определяющих той или иной теории, является предсказание новых фактов, до того времени не наблюдавшихся. Что можно предсказать, ис- пользуя предлагаемый нами вариант системы элементов? Вот лишь один пример на этот счет.

Давно замечено, что 5 -АО по числу используемых для образования химических связен электронов весьма напоминает $4 d$-AO: U по своим возможным степеням окисления повторяет Мо, $\mathrm{Np}$ $\mathrm{Tc}, \mathrm{Am}-\mathrm{Rh}$ и $\mathrm{Pd}-\mathrm{Cm}$. Поэтому можно ожидать, что аналогичное сходство должно отмечаться и в степенях окисления пары Ru-Pu. Максимальная степень окисления $\mathrm{Ru}$, как известно, равна +8 и в рамках именно «полудлиннопериодического» варианта можно ожидать, что такая же степень окисления должна проявляться и у $\mathrm{Pu}$. И относительно недавно [45] были получены химические соединения, где $\mathrm{Pu}$ действительно проявляет эту степень окисления. Более того, можно даже ожидать, что «сосед» $\mathrm{Pu}$ по таблице химических элементов - Am окажется способным проявить степень окисления +9 (на данный момент «документально зафиксированная» максимальная степень окисления этого элемента - +7). Правда, ни для одного из 118 известных химических элементов такая степень окисления до сих пор в эксперименте не отмечалась....

Заканчивая этот параграф, отметим, что в свое время был предложен довольно интересный табличный вариант интерпретации Периодического Закона, который может рассматриваться как некий «гибрид» «короткопериодического» с предлагаемым нами «полудлиннопериодическим» (Рис. 24). В нем, как можно видеть, лантаноиды и актиноиды, равно как и в «полудлиннопериодическом» варианте, находятся в группах 1-14, причем Tm и $\mathrm{Md}-$ именно в первой, $\mathrm{Yb}$ и No - именно во второй, $\mathrm{Lu}$ и $\mathrm{Lr}$ - в третьей, как и в «полудлиннопериодическом» варианте; аналогичное сходство можно отметить и в положении многих других элементов. Однако в нем остаются все те же семь периодов, и шесть пустых клеток, что и в «короткопериодическом» варианте, а водород и инертные газы помещены в седьмую и восьмую группы соответственно, что с их свойствами, прямо скажем, не шибко хорошо согласуется... Есть и совсем странная модификация «короткопериодическо-го» варианта системы элементов (Рис. 25), представленная на веб-сайте [47], где инертные газы (почему-то) помещены во II группу вместе с ничего не имеющими с ними общего $s$ - и $d$-элементами II группы (Ca, Zn и др.) и $4 f$-элементом Yb. И тем более странно, что, если верить написанному на этом же самом сайте [47], сию Периодическую систему химических элементов рекомендует для использования не кто иной, как ... сам IUPAC (!!). Этот модифицированный «короткопериодический» вариант, кстати, был предложен сравнительно недавно, в 2010 г. 


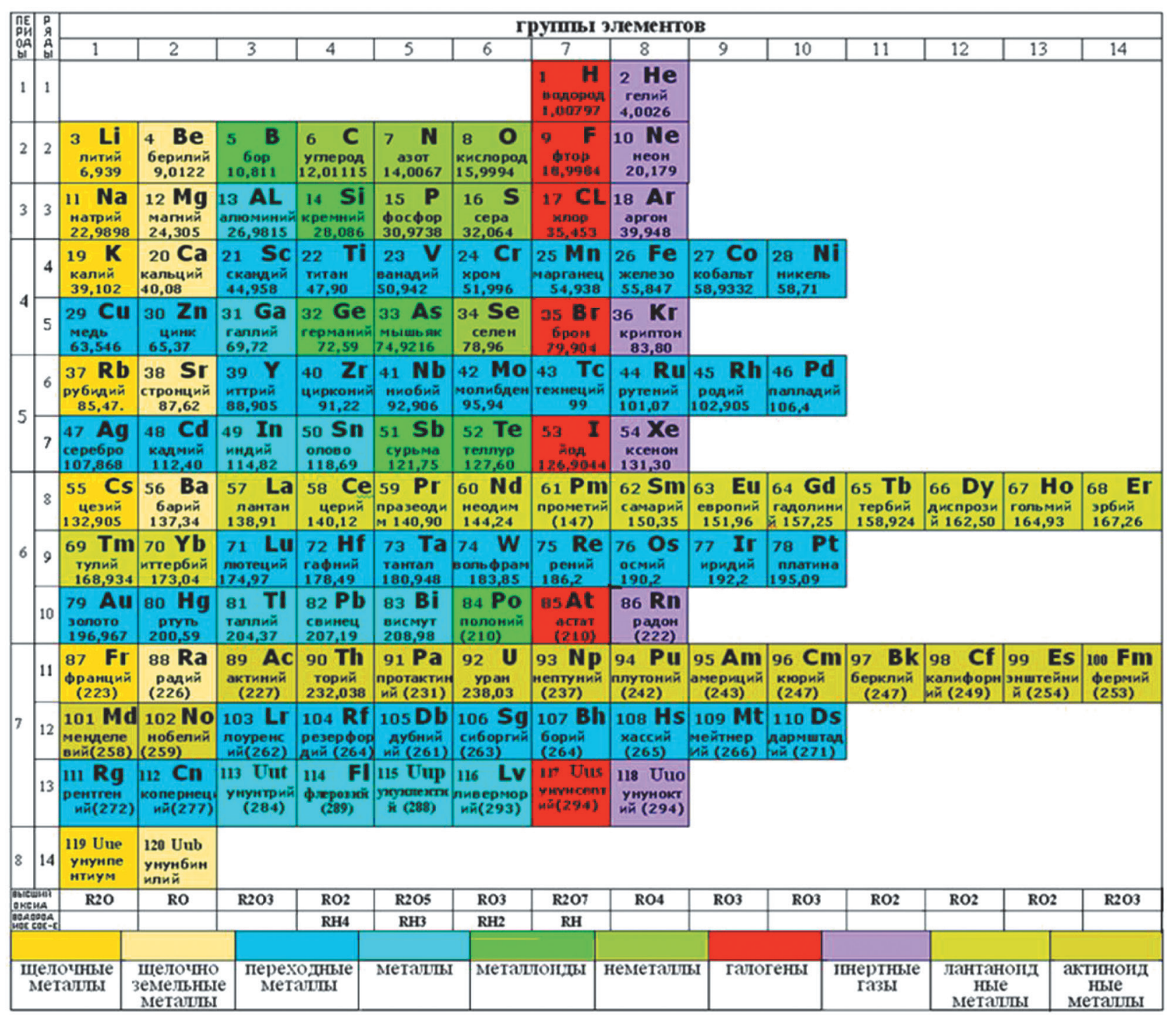

Рис. 25. «Гибридный» 14-клеточный вариант системы химических элементов, являющийся неким промежуточным между «короткопериодическим» и «длиннопериодическим» вариантами [46]

\section{Проблемы верхней границы Периодической системы химических элементов}

Вопрос о том, сколько вообще существует химических элементов, возник едва ли не сразу же после того, как Д.И. Менделеев сформулировал Периодический Закон, носящий его имя. Самым тяжелым химическим элементом, обнаруженным в природе, в настоящее время принято считать уран в лице его изотопа ${ }^{92} \mathrm{U}^{238}$. Но это если оценивать степень «тяжести» по массе ядра, состоящего, как известно, из протонов и нейтронов; если же оценивать степень «тяжести» по заряду ядра (т.е. по числу одних лишь протонов), то самым тяжелым придется признать нептуний в лице его изотопа ${ }^{93} \mathrm{~Np}^{237}$. Оба этих изотопа, однако, радиоактивны с периодами полураспада $T_{1 / 2}=4.4 \cdot 10^{9}$ лет и $2.2 \cdot 10^{6}$ лет соответственно. Самый же тяже- лый элемент, который устойчив (т.е. не подвержен радиоактивному распаду) - это свинец в лице его изотопа ${ }^{82} \mathrm{~Pb}^{208}$.

Согласно правилам, сформулированным нашим соотечественником В.М. Клечковским в работах [48-51], порядок заполнения электронами атомных орбиталей регламентируется значениями главного $(n)$ и орбитального $(l)$ квантовых чисел соответствующих АО. А именно: чем выше сумма значений $(n+l)$, тем большую энергию имеет АО и соответственно, позднее заполняется электронами; если же для двух или большего числа АО $(n+l)$ одинакова, то энергия АО тем выше, чем больше величина $n$. С учетом только что сказанного последовательность заполнения АО для первых десяти периодов в рамках «короткопериодического» и «длиннопериодического» вариантов (или пяти периодов в рамках «полудлиннопериоди- 


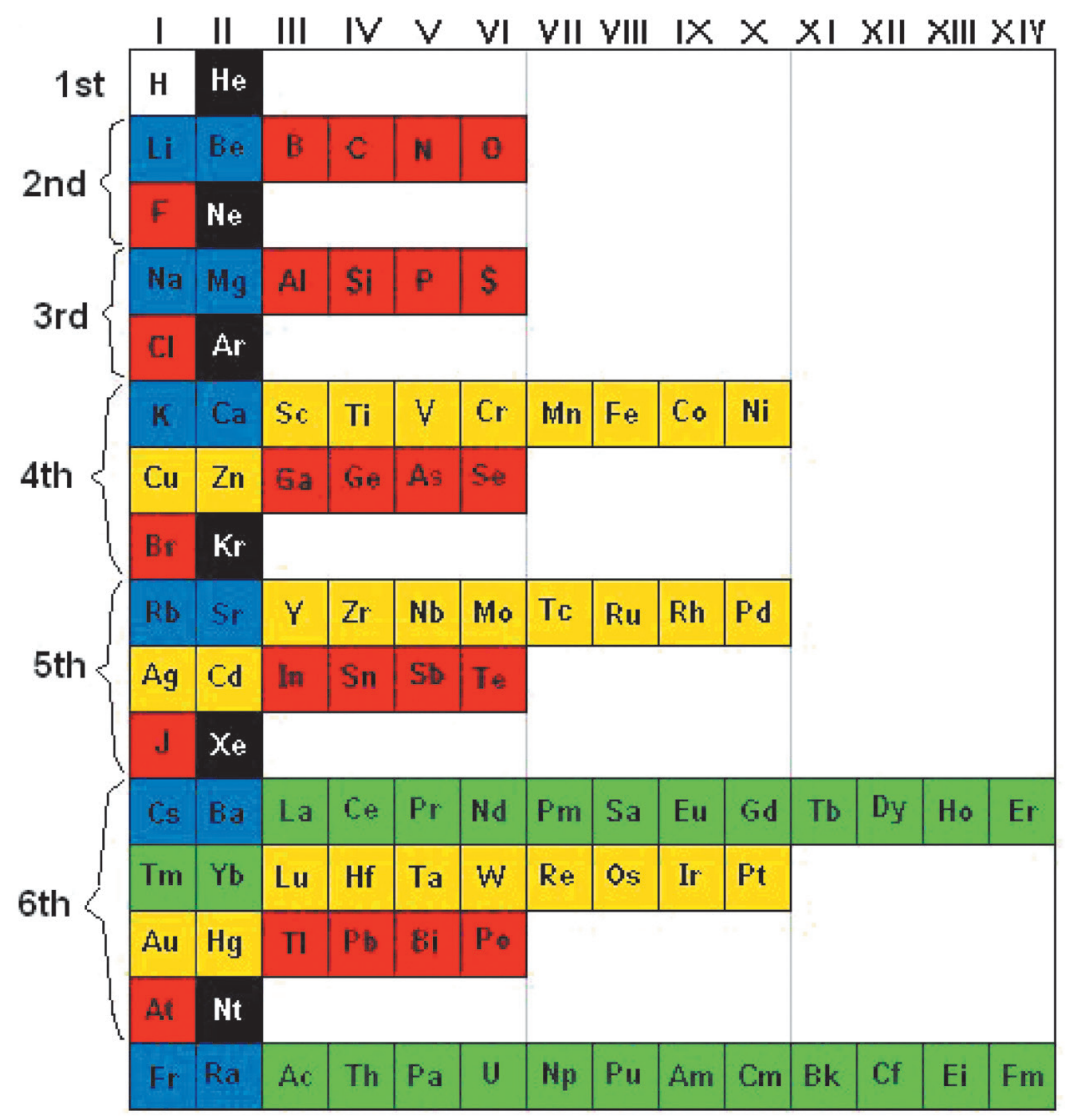

Рис. 26. Модифицированный «короткопериодический» вариант Периодической системы [47]

ческого» варианта), как нетрудно показать, будет следующей: $1 s, 2 s, 2 p, 3 s, 3 p, 4 s, 3 d, 4 p, 5 s, 4 d, 5 p$, $6 s, 4 f, 5 d, 6 p, 7 s, 5 f, 6 d, 7 p, 8 s, 5 g, 6 f, 7 d, 8 p, 9 s, 6 g$, $7 f, 8 d, 9 p, 10 s, 6 h, 7 g, 8 f, 9 d, 10 p, \ldots$ Соответственно этому в первом периоде «короткопериодического» и «длиннопериодического» вариантов - 2 элемента, во втором и третьем - по 8, в четвертом и пятом - по 18 , в шестом и седьмом - по 32 , в восьмом и девятом - по 50, в десятом - 72, в сумме же 290 элементов. Это намного больше, чем их число, которое известно на данный момент (118).

Как уже упоминалось нами в начале данной статьи, мнения различных исследователей относительно общего числа химических элементов весьма сильно расходятся. И отнюдь не факт, что десятый период - это конец «мира» химических элементов. В [52] утверждается, что «с позищий структурной организации электронных систем атомов химических элементов в плоскости орбитального квантового числа, последним элементом Периодической системы Д.И. Менделеева является элемент с порядковым номером 118, который замыкает седьмой химический период». Это, однако, было написано в 2005 г., и пока не получен хотя бы следующий по счету 119-й элемент, его нельзя считать опровергнутым. В связи с этим примечательно, что попытки его получения предпринимались уже неоднократно, но даже и одного (!) нуклида с таким зарядом в эксперименте зафиксировать пока что не удалось. В результате на данный момент времени в номенклатуре химических элементов даже сложилась невиданная ранее ситуация, когда всем официально открытым и зарегистрированным сверхтяжелым химическим элементам те или иные тривиальные названия были присвоены ДО того, как будет открыт какой-либо из следующих по счету химических элементов (напомним в связи с этим, что по сложившейся ныне традиции всем открытым элементам первоначально присваивается систематическое название по номенклатуpe IUPAC, представляющее собой некое производное от порядкового латинского числительного, соответствующего заряду ядра нуклида данного элемента, например элемент 116 - ливерморий Lv до присвоения ему данного названия в Периодической системе значился как унунгексий). Сравнительно долгое время было распространено несколько другое мнение, согласно которому «верхняя граница существования атомных структур материи должна соответствовать значению $Z=137$, 
которое вытекает из квантово-механических расчетов» [53]. Со временем, однако, эта верхняя граница сдвигалась лишь в сторону ее увеличения. В частности, согласно сведениям, представленным в [3,54], В.И. Гольданский вычислил, что Периодическая система может включать в себя ни много ни мало $10^{10}(!)$ химических элементов и будет состоять из 3910 периодов, причем в последнем из них должно быть 7.659.698 элементов. Эта цифра нашла определенное (пусть и косвенное) подтверждение в работе Ю.С. Черкинского [55], который, изучая динамику изменения значений стандартных энтропий образования $\left(S_{f, 298}^{0}\right)$ инертных газов и тех элементов, простые вещества которых при стандартных условиях находятся в твердом агрегатном состоянии (и соответственно, формально имеют полимерную структуру), обнаружил, что прямые на зависимостей $S_{f, 298}^{0}=f(\operatorname{lgZ})$ для этих объектов пересекаются в точке $\lg Z=10$, на основании чего и пришел к заключению, что самый тяжелый элемент должен имеет порядковый номер $\mathrm{Z} \sim 10^{10}$. Если так, то радиус его нуклида (в состав которого должно входить не менее чем $10^{10}$ нейтронов) согласно известной эмпирической формуле $\mathrm{R} \approx 1.3 \mathrm{~N}^{1 / 3}$ [фм], где $\mathrm{R}$ - радиус нуклида, $\mathrm{N}$ - число содержащихся в нем протонов и нейтронов [56] должен составить $3.5 \cdot 10^{-12}$ м, а поскольку радиус нуклида примерно на четыре порядка меньше радиуса атома [56], то последний для такого элемента окажется $\sim 3.5 \cdot 10^{-8}$ м, т.е. 35 нм и он попадет в категорию наночастии. В работе [3] были даны весьма противоречивые оценки величины номера Z самого тяжелого химического элемента: с одной стороны, было постулировано, что это значение близко к значению квадратного корня из числа Авогадро, а именно $7.8 \cdot 10^{11}$ (в основе чего лежало представление о связи Периодической системы с т.н. числами Фибоначчи, отмеченное в [17]), с другой - что оно может быть связано с известным выражением зависимости энергии $\mathrm{AO}\left(\mathrm{E}_{\mathrm{n}}\right)$ от номера главного квантового числа $n$, получаемого из решения уравнения Шредингера $\mathrm{E}_{\mathrm{n}}=\mathrm{E}_{0} / n^{2}$, где $\mathrm{E}_{\mathrm{o}}=2,17987190 \cdot 10^{-18}$ Дж [57], при допущении, что что минимальное значение $\mathrm{E}_{\mathrm{n}}$ есть не что иное, как постоянная Планка $h=6,62606876 \cdot 10^{-34}$ Дж·с, откуда это самое число $Z=5.7357143 \cdot 10^{7}$. Расхождение, как видим, весьма значительное - четыре (!) порядка, так что сам подобный подход к оценке этого самого предельного значения заряда нуклида становится весьма сомнительным. Эти сомнения усиливаются, если вспомнить и такой хорошо известный экспериментальный факт: по мере возрастания заряда $\mathrm{Z}$ способность атомов химического элемента к радиоактивному распаду на более легкие элементы довольно резко растет, а, соответ- ственно, резко падает и их устойчивость. Во всяком случае, период полураспада сверхтяжелых $7 p$-элементов $T_{1 / 2}$ измеряется долями секунды, и вроде бы налицо все симптомы того, что предел по величине Z уже близок. Однако здесь есть и другой момент, который настраивает на оптимистический лад. Дело в том, что, согласно т.н. теории оболочечного строения нуклидов заполнение протонов и нейтронов в атомных ядрах происходит примерно так же, как и электронов на АO, и подобно тому, как атомы с полностью заполненными электронными слоями отличаются повышенной устойчивостью в химических превращениях, нуклиды с полностью заполненными протонными или же нейтронными оболочками также характеризуются повышенной устойчивостью к радиоактивному распаду. В случае нуклидов таковыми оказываются ядра, содержащие 2, 8, 20, 50, 82, 114, 126 или 164 протонов и 2, 8, 20, 28, 50, 82, 126, 184, 196, 228, 272 или 318 нейтронов; эти числа получили в ядерной физике название «магических чисел». (В связи обращает на себя внимание тот факт, что ядро самого тяжелого химического элемента, не подверженного радиоактивному распаду, а именно ${ }^{82} \mathrm{~Pb}^{208}$, является «дважды магическим», ибо в нем «магическое» число протонов (82) и «магическое» число нейтронов (126). Правда, оболочечная модель ядра на сегодняшний момент по большому счету является лишь полуэмпирической схемой, позволяющей хоть как-то понять некоторые закономерности в структуре ядер, но не способной до конца последовательно количественно описать их свойства. К тому же порядок заполнения как протонных, так и нейтронных оболочек зависит, во-первых, от характера силового поля, которое определяет индивидуальные состояния квазичастиц, и, во-вторых, от смешивания конфигураций (хотя последнее обычно принимается во внимание лишь при рассмотрении незаполненных оболочек (как протонных, так и нейтронных). Следует отметить то важное обстоятельство, что в реализованных до сих пор синтезах сверхтяжелых ядер с Z>110 образовывались нуклиды с дефицитом нейтронов, в результате чего и наблюдалась их резко выраженная нестабильность по отношению к радиоактивному распаду. Для получения сколько-нибудь устойчивых нуклидов со столь значительными Z, как считают физики-ядерщики, необходимо добиться наличие в нем числа нейтронов, равное хотя бы следующему для них после 126 магическому числу, а именно 184 [58]. Проблемы синтеза сверхтяжелых нуклидов химических элементов с Z>110 детально рассмотрены в ряде публикаций (см., в частности, обзоры [53, 58-61]). Так что вопрос о верхней границе Периодической системы, 
т.е. о максимальном значении $\mathrm{Z}$ остается неясным и поныне, тем более что возрастающая нестабильность нуклидов с ростом величины $Z$ помимо всего вышесказанного обусловлена еще и наличием т.н. «релятивистского эффекта», а именно - возрастания массы электронов, скорость движения которых в очень тяжелых атомах становится сопоставимой со скоростью света. Учет этих эффектов предполагает, в частности, весьма сильное сжатие $7 s-$ и $7 p$-АО. В связи с этим, например, можно полагать, что для коперниция $\mathrm{Cn}(\mathrm{Z}=112)$ («экартути», как, наверное, выразился бы сам Д.И. Менделеев), и флеровия $\mathrm{Fl}(\mathrm{Z}=114)$ («экасвинца») будет иметь место весьма низкая реакционная способность и по своим свойствам оба они должны быть близки к благородным газам (!) подобно радону $\mathrm{Rn}(\mathrm{Z}=86)$. Согласно [58, С. 1172], большинство теоретических предсказаний относительно коперниция сводится к тому, что в виде простого вещества он должен обладать весьма значительной летучестью и, возможно, даже быть газообразным (!) при комнатной температуре. Если вспомнить о том, что аналоги $\mathrm{Cn}$, а именно - $\mathrm{Cd}$ и $\mathrm{Hg}$ в виде простых веществ при комнатной температуре обладают твердым и жидким состоянием соответственно, то подобный вывод в общем-то не покажется удивительным (ибо для простых веществ этих $d$-элементов II группы получается, что с увеличением главного квантового числа $n$ имеет место снижение температур плавления и кипения). Однако есть и другое мнение, согласно которому $\mathrm{Cn}$ должен быть благородным металлом вследствие релятивистского расщепление $6 d-\mathrm{AO}[58$, С. 1172]. «Масла в огонь» подливает и возрастание неустойчивости электронных оболочек с ростом $Z$, которая отчасти связана со сближением энергий АО по мере возрастания значений главного $n$ и орбитального $l$ квантовых чисел. Так, если каким-либо образом в будущем удастся получить (а возможно, даже и обнаружить в природе) элементы с номерами 122 и более, то с учетом только что сказанного весьма вероятно, что в них будет иметь место «смешение» $5 g$-уровня и следующего за ним по энергии $6 f$-уровня. А раз так, то возникнет уникальная ситуация, когда про отдельные из этих элементов уже будет нельзя говорить, что они являются именно $5 g$-элементами, потому что в их электронных конфигурациях основного состояния будут присутствовать не только $5 g$-, но и $6 f$-электроны (а возможно, даже и $7 d$-электроны). Проще говоря, эти элементы уже нельзя будет отнести ни к $5 g$-, ни $6 f$-элементам, это будут некие «гибридные» элементы между ними. И потому весьма симптоматичными, но вполне справедливыми представляются слова одного из ведущих наших отечественных специалистов в области ядерной физики, директора Лаборатории ядерных реакций им. Г.Н. Флерова Объединенного Института ядерных исследований профессора С.Н. Дмитриева, произнесенные им 26 сентября 2016 г. во время чтения пленарного доклада [62] на предыдущем, XX Менделеевском Съезде по общей и прикладной химии: «Похоже на то, что мы уже вплотную подошли к тому месту в Периодической системе химических элементов, когда Периодический Закон Д.И. Менделеева перестает выполняться».

\section{Заключение}

В свое время, после того как Периодический Закон уже получил признание среди химиков-современников, Д.И. Менделеев, говоря о его перспективах на будущее, произнес весьма примечательную фразу: «Периодическому Закону не угрожает разрушение, а лишь надстройка обещается...». И действительно, 150 лет, прошедших с момента открытия этого Закона, в полной мере подтвердили это предсказание его первооткрывателя хотя бы уже тем, что в процессе его эволюции были предложены не одна и не две сотни самых разных вариантов этой самой «надстройки» (т.е. интерпретации Периодического Закона с использованием тех или иных систем химических элементов в графическом формате), и изыскания на этой ниве, судя по всему, еще отнюдь не закончены. При этом подавляющее большинство созданных в разное время графических вариантов либо так и не получило сколько-нибудь широкого распространения, либо вообще осталось незамеченным; парадоксально, что по иронии судьбы признание среди исследователей получили лишь два варианта - «короткопериодический», созданный самим первооткрывателем Периодического Закона, и «длиннопериодический», к которому Д.И. Менделеев, похоже, также «приложил руку». Заметим в связи с этим, что, несмотря на обилие вариантов интерпретации Периодического Закона, какой-либо значимой математической формуль, связывающей меж собой какое-либо макроскопическое свойство химического элемента из числа «ключевых» (плотность, электрическая проводимость, температура плавления/кипения и др.) и заряд нуклида, до сих пор так и не найдено (во всяком случае, такой, которая получила всеобщее признание среди физиков и химиков, и широко использовалась бы ими на практике). Но как бы то ни было, Д.И. Менделеев оставил после себя подлинно великое наследие, которое имеет все основания для того, чтобы и в будущем продолжать его реализовывать и по возможности - совершенствовать. 


\section{Лuтература}

1. Левченков С.И. Краткий курс истории химии. Ростов, Изд. ЮФУ, 2013. С. 57-67.

2. Миттова И.Я., Самойлов А.М. История химии с древнейших времен до конца ХХ века. Учебное пособие. В 2 т. Долгопрудный: Издательский Дом «Интеллект», 2012. Т. 2. С. 120-174.

3. Саркисов Ю.С. Вестник Томского гос. ун-та, Химия. 2017. №9. C. 83-89.

4. Newlands J.A.R. Chem. News. 1863. V. 7. P. 70-86.

5. Newlands J.A.R. Chem. News. 1865. V. 12. P. 83-84.

6. Meyer L. Die moderernen Theorien der Chemie und ihre Bedeutung fur die Chemische Statik. Breslau, Maruschke and Berendt, 1864. S. 137.

7. Meyer L. Ann. Chem. Pharm. Suppl. 1870. B. VII. H. 3. S. 354-364.

8. Менделеев Д.И. Основы химии. СПб.: Типо-литография М.П. Фроловой, 1869. Ч. 1. С. 8.

9. Менделеев Д.И. Журн. Рус. Хим. Общества, 1869. T. 1. C. $60-67$.

10. Mendelejeff D. Zeitschrift fur Chemie, 1869. B. 5. S. 405-406.

11. История открытия благородных газов. Режим доступа в Internet: http://www.apxu.ru/article /plapla/ bibb/blago/ictoria_otkrytia_blagorodnyh gazov.htm

12. Ахметов Н.С. Общая и неорганическая хнмия. Москва, Высшая Школа, 1988. С. 38.

13. International Union of Pure and Applied Chemistry. Официальный сайт: http://iupac.org/

14. Karola P.J., Barber R.C., Sherrill B.M., Vardaci E., Yamazaki T. Pure Appl. Chem., 2016. V. 88. N 1. P. 139-153.

15. Karola P.J., Barber R.C., Sherrill B.M., Vardaci E., Yamazaki T. Pure Appl. Chem., 2016. V. 88. N 1. P. 155-160.

16. Hamilton H., Hofman S., Oganessian Y.T. Annual Rev. Nucl. Part. Sci., 2013. V. 63. N 2. P. 383-405.

17. Якушко С.И. «Фибоначчиевая» закономерность в периодической системе элементов Д.И. Менделеева. Режим доступа в Internet: http://www.trinitas.ru/ rus/doc/0016/001c/1662-jak.pdf

18. Варианты периодической системы Менделеева. Режим доступа в Internet: https://www.google.com/search ?q=варианты + периодической + системы + менделеева

19. Открытие длиной 200 лет. Режим доступа в Internet: https://oko-planet.su/science/sciencenews/ 441763-otkrytie-dlinoyu-200-let.html

20. Wikipedia. Альтернативные периодические таблицы. Режим доступа в Internet: https://ru.wikipedia. org/wiki/Альтернативные_периодические_таблицы

21. Варианты периодической системы [1972 Семишин В.И. Периодическая система химических элементов Д.И. Менделеева]. Режим доступа в Internet: http:// chemlib.ru/books/item/f00/s00/z0000034/st010.shtml

22. Альтернативная система элементов Теодора Бенфея. Режим доступа в Internet: https:// shkolazhizni. ru/world/articles/47658/

23. Экзотические варианты периодической таблицы. Режим доступа в Internet: https://design. artgorbunov. ru/ekzoticheskie-variant-periodicheskoy-tablitsymendeleeva/

24. Cyclical Continuum of Elemental Properties by Robert R. Northup. Режим доступа в Internet: www.cyclicalcontinuum.com

25. Альтернативные периодические таблицы. Режим доступа в Internet: http://www.wikiwand.com/ru /Альтернативные_периодические_таблицы

26. Website в Internet: http://int-46.ucoz.ru/Janets-SpiralPeriodic-Table-499x448.png

27. Спиральные и объемные формы таблицы Менделеева. Режим доступа в Internet: https://www.liveinternet. ru/users/2391301/post69842048/

28. Website in Internet https://lenta.ru/news/2009/10/07/ mendeleev/

29. Website in Internet https://studfiles.net/preview/5909709/page:11/

30. Website in Internet https://bureau.ru/content/images/ dd/original/1427110429-pfractal-1.gif

31. База данных некоторых альтернативных периодических таблиц. Режим доступа в Internet: https://www. meta-synthesis.com/webbook/35_pt/pt_database.php

32. Website в Internet: http://int-46.ucoz.ru/load/12-1-0-231

33. Гердев Б.Н. Естественная сотовая система химических элементов Б.Н. Гердева (2010). Режим доступа в Internet: http://gerdev-sota.narod.ru

34. Галушкин Ю.А., Егорова М.Ю., Сидорова М.И. Устойчивое инновационное развитие: проектирование и управление. 2015. Т. 1, № 1. С. 51-54.

35. Galoushkin Y.A., Gusev B.V., Samuel Yen-Liang Yin, Speransky A.A. Fundamental triad of knowledge and Laws of its volume periodicity in structure of physical-chemical elements. 2015. Dubna, V International scientific conference of the State University "Dubna". URL: http://www.yrazvifie.ru

36. Махов Б.Ф. Фундаментальные исследования, 2008. №3. С. 25-28.

37. Базиев Д.Х. Современная наука: актуальные проблемы теории и практики. Сер. Естественные и технические науки, 2011. № 1. С. 54-64.

38. Mazurs E.G. Graphic Representations of the Periodic System During One Hundred Years. 2nd Ed. Alabama, 1974. 224 p.

39. Имянитов Н.С. Природа, 2002. №6. С. 62-69.

40. Михайлов О.В. Высшее образование в России, 2016. №5. C. 156-160.

41. Киселев Ю.М., Третьяков Ю.Д. Успехи химии, 1999. T. 68. №5. C. 401-415.

42. Реми Г. Курс неорганической химии. Т. 2. Москва, Мир. 1966. 717 с.

43. Некрасов Б.В. Основы общей химии. Т. 1. Москва, Химия, 1965. 518 с.; Т. 2. Москва, Химия, 1967. 399 с.; Т. 3. Москва, Химия, 1970. 415 с.

44. Коттон Ф.А., Уилкинсон Дж.Б. Современная неорганическая химия. Т. 3. Москва, Мир, 1969. 592 с.

45. Никонов М.В., Мясоедов Б.Ф. Радиохимия, 2010. T. 52. № 1. C. 16-30.

46. Web-site in Internet http://atom21.ru/4ast1.htm

47. Web-site in Internet https://golos.io/ru--khimiya/@boltyn/ na-vkus-i-cvet-tablicy-d-i-mendeleeva-byvayut-raznye 
48. Клечковский В.М. Докл. АН СССР. 1951. Т. 80. N 4. C. 603-606.

49. Клечковский В.М. Докл. АН СССР. 1952. Т. 86. N 4. С. 691-694.

50. Клечковский В.М. ЖЭТФ. 1953. Т. 25, N 2. С. 179-187.

51. Клечковский В.М. Распределение атомных электронов и правило последовательного заполнения $(\mathrm{n}+1)-$ групп. М., 1968. С. 290-292.

52. Вяткин В.Б. Ergo. Проблемы методологии междисциплинарных исследований и комплексного обеспечения научно-исследовательской деятельности. 2005. Вып. 4. Режим доступа в Internet: http:// vbvvbv.narod.ru/Mendeleev170/g3/index.htm

53. Сергина М.Н., Зимняков А.М. Изв. Пензенского государственного педагогического университета им. В.Г. Белинского. 2006. № 1. №5. С. 231-234.

54. Формирование современной естественнонаучной парадигмы. Сб. / под ред. Л.Б. Баженова, С.Н. Коняева // Философия науки. 2001. Вып. 7. 270 с.

55. Черкинский Ю.С. Химия и жизнь. 1973. №9. С. 2-6.

56. Web-site in Internet http://nuclphys.sinp.msu.ru/anuc/ anuc01.htm

57. Фундаментальные физические постоянные (1998)/ пер. А.А. Радцига // Успехи физических наук, 2003. Т. 173. №3. С. 339-343.
58. Оганесян Ю.Ц., Дмитриев С.Н. Успехи химии, 2009 78, №12. C. 1165-1176 [Oganessian Yu. Ts., Dmitriev S.N. Russ. Chem. Rev. 2009. V. 78. N 12. P. $1077-$ 1087]

59. Yu.Ts. Oganessian, V.K. Utyonkov, Yu.V. Lobanov, F.Sh. Abdullin, A.N. Polyakov, I.V. Shirokovsky, Yu.S. Tsyganov, G.G. Gulbekian, S.L. Bogomolov, B.N. Gikal, A.N. Mezentsev, S. Iliev, V.G. Subbotin, A.M. Sukhov, G.V. Buklanov, K. Subotic, M.G. Itkis, K.J. Moody, J.F. Wild, N.J. Stoyer, M.A. Stoyer, and R.W. Lougheed. Phys. Rev. Lett., 1999. V. 83. N 16. P. 3154-3157.

60. Hamilton J.H., Hofmann S., Oganessian Yu.Ts. Annual Rev. Nucl. Part. Sci. 2013. V. 63. N 1. P. 383-405.

61. Ииханов Б.С., Третьякова Т.Ю. Вестник МГУ, Сер. 3 - Физика, Астрономия, 2017. №3. С. 3-20.

62. Дмитриев С.Н., Оганесян Ю.Ц. Сверхтяжелые элементы Периодической таблицы Д.И. Менделеева. XX Менделеевский съезд по общей и прикладной химии (Екатеринбург, 26-30 сентября 2016). Тезисы докладов в пяти томах, Т. 1. С. 24 [Dmitriev S.N., Oganessian Yu.Ts. Superheavy elements of the Periodic table of D.I Mendeleev. XX Mendeleev Congress of General and Applied Chemistry, (Ekaterinburg, September 26-30). Abstract Book in 5 volumes. V. 1. P. 15]. 